\title{
Two isostructural halogen derivatives of 9-ethylcarbazole: crystal structure, Hirshfeld surface analysis, and structural comparison with other simple analogs
}

\author{
Ewa Rozycka-Sokolowska • Bernard Marciniak • \\ Sebastian Kosik • Barbara Dondela • \\ Zygmunt Bak
}

Received: 25 September 2014/ Accepted: 18 November 2014/Published online: 31 January 2015

(C) The Author(s) 2015. This article is published with open access at Springerlink.com

\begin{abstract}
This article describes a detailed study of the molecular packing and intermolecular interactions in crystals of two derivatives of 9-ethylcarbazole, i.e., 3-chloro- and 3-bromo-9-ethylcarbazole (1 and 2, respectively). A significance of this study lies both in the comparison drawn between the crystal structures of these compounds and those of several of their simple analogs [i.e., 3,6-dibromo-9-ethylcarbazole (3), 3,6-dibromo-9methylcarbazole (4), 3,6-dibromocarbazole (5), 3-bromocarbazole (6), 3,6-diiodocarbazole (7), 9-ethylcarbazole (8), 9-methylcarbazole (9) and carbazole (10)], and in the preliminary assessment of their suitability as active materials for organic electronics. This comparison shows a close similarity in the packing of molecules of three of them (i.e., $3,4,6)$ that form the $\pi$-stacks along the shortest crystallographic axes, with a substantial spatial overlap between adjacent molecules in the stacks, depending mainly on the length of substituent at position 9 of carbazole skeleton and on the ratio of $(\% \mathrm{C} \cdots \mathrm{H}) /(\% \mathrm{C} \cdots \mathrm{C})$ interactions. Similar to them, in the crystal structures of $\mathbf{1}$ and $\mathbf{2}$ there is slipped face-to-face $\pi \cdots \pi$ interaction, but in contrast this interaction connects two molecules of these compounds into the dimers that are further connected by $\mathrm{C}-\mathrm{H} \cdots \pi$ interaction. The molecular packing in crystals of these compounds is intermediate between the arrangement of molecules of $\mathbf{3}, \mathbf{4}$,
\end{abstract}

E. Rozycka-Sokolowska ( $₫) \cdot$ B. Marciniak · S. Kosik ·

B. Dondela

Institute of Chemistry, Environmental Protection and

Biotechnology, Jan Dlugosz University in Czestochowa,

Armii Krajowej 13/15, 42-201 Czestochowa, Poland

e-mail: e.sokolowska@ajd.czest.pl

Z. Bak

Institute of Physics, Jan Dlugosz University in Czestochowa,

Armii Krajowej 13/15, 42-201 Czestochowa, Poland and $\mathbf{6}$, where the slipped $\pi$-stacking is predominant, and the typical herringbone packing in compounds 5 and 7-10. Thus, it can be supposed that out of ten compounds analyzed here, only 3, 4, and $\mathbf{6}$ will turn to be the most promising materials for device applications (particularly for field-effect transistors).

Keywords X-ray · Hirshfeld surface analysis . Intermolecular interactions · Carbazoles · Organic electronics

\section{Introduction}

Modern electronics, aiming to further material- and energyefficient miniaturization and the consequent cheapening of the electronic and optoelectronic devices increasingly dominant in our daily life, (e.g., TV, bank cards, computer screens, etc.), is increasingly focused on the use of properties and phenomena occurring in the ever growing group of diverse semi-conductive organic materials, which include both compounds with low molecular weight ("small molecules", SM) and small oligomers, and macromolecular polymers $[1,2]$. It is worth noting that in the case of SM and oligomers, there is a widely developed search for new, high-performance active materials for organic electronics, focused mainly on the chemically and thermally stable compounds that contain rigid skeletons of aromatic and heteroaromatic hydrocarbons (AHs and HHs). Rigid skeletons of molecules of such compounds are currently being widely used as basic structural units in the syntheses, which lead to one of the most promising groups of active materials for the new generation of low-cost, flexible, electronic and optoelectronic devices such as photovoltaic and solar cells, organic light emitting diodes 
(OLEDs), and organic field-effect transistors (OFETs) [36]. Their potential practical applications include, for example, foldable flat panel displays, light flexible largesize displays with very high color fidelity, active matrixes for liquid crystal displays, radio frequency scanners, chemical and biological sensors, the electronic "paper" or electronic barcodes [1, 2, 7-9]. Taking into account the fact that the typical herringbone (HB) packing of molecules in the solid-state structures of unsubstituted AHs and $\mathrm{HHs}$ is not very beneficial, especially in terms of electrical performance of OFETs (a measure of this performance is the mobility of the charge carriers) and high efficiency photovoltaic and solar cells, attempts to improve the arrangements of molecules through modifying the intermolecular interactions governing the solid-state packing, have been a field of intensive research in recent years [10-18]. These attempts include the chemical modification of molecules of these hydrocarbons through the introduction of substituents on their periphery, and the construction of multicomponent molecular solids or co-crystals. For example, as it is shown in our previous papers [19-21], the introduction of the simple substituents $\left(\mathrm{OH}, \mathrm{NH}_{2}, \mathrm{OCH}_{3}\right.$, and particularly halogen substituents) to the molecule of the simplest polycyclic $\mathrm{AH}$, i.e., naphthalene, leads to a change in the packing of aromatic skeletons of this hydrocarbon, from the typical HB arrangement, to the more advantageous $\pi$ stacking with considerable overlapping of $\pi$-electron orbitals between adjacent molecules in the stack. Such situations took place in the case of 1-naphthol (refcode in Cambridge Structural Database (CSD) [22]: NAPHOL01 [23]) and naphthalene derivatives carrying different substituents at positions 4 or 5, i.e., 4-chloro-, 4-methoxy- and 5-amino-1-naphthol (CSD refcodes: BOTSOT [19], CUFKOE [20] and FUHTAE01 [21], respectively), 1,4-dihydroxy-, 1,4-dichloro- and 1,4-dibromonaphthalene (CSD refcodes: NPHHQU10 [24], DCLNAQ [25] and DBRNAQ01 [26], respectively) and 1,5-dihydroxynaphthalene (VOGRUE [27]). Moreover, it is interesting to note that generally the values of area overlap (AO) estimated for them, using the geometric model proposed by Janzen et al. [12], depended on the substituent type. Interestingly, analyzing crystal structures of di-substituted naphthalene derivatives such as 1,3-, 1,6-, 1,7-, 2,3-, 2,6-, and 2,7dihydroxynaphthalene (CSD codes: HEGFAB [28], RIGMOK [29], LICKEO [30], VOGSEP [27], VOGSAL [27], and NPHLDL01 [31], respectively) and of 2-naphthol (NAPHOB03 [32], it was easy to notice that the molecular modification involving introduction of at least one substituent into the $\beta$ position of naphthalene skeleton does not result in the same transformation of packing molecules into stacks as the earlier one.

This paper is a continuation of our structural studies [19-21, 33, 34] related with the exploration of active materials useful for modern organic electronics. We plan to focus here on the non-tested so far in this respect two halogen 9-ethylcarbazole derivatives of unknown crystal structures (CSD), and on seven of their simple analogs (Scheme), i.e., compounds such 3,6-dibromo-9-ethylcarbazole (3;CSD refcode: DATJOY [35]), 3,6-dibromo-9methylcarbazole (4; CSD refcode: MASCAL [36]), 3-bromo-carbazole (5; CSD refcode: DATJOY [37]), 3,6dibromocarbazole (6; CSD refcode: MASBUE [36]), 3,6diiodocarbazole (7; CSD refcode: YAYDUZ [38]), 9-ethylcarbazole (8; CSD refcode: ETCABZ10 [39]) and 9-methylcarbazole (9; CSD refcode: NMCABZ [40]). The primary goal of this paper is to determine the factors influencing the packing of molecules in the crystals of this group of carbazole derivatives, the knowledge of which makes it possible their preliminary assessment as active materials for organic electronics. Thus, we not only present here the results of X-ray studies of crystals of 3-chloro- and 3-bromo-9-ethylcarbazole ( $\mathbf{1}$ and $\mathbf{2}$ ), but also we concentrate on possibly the most precise characterization of mutual arrangement of molecules in the crystals and intermolecular interactions, and we compare these structural properties with those of compounds 3-9 and unsubstituted carbazole (10; CSD refcode: CRBZOL03 [41]).

It is noteworthy that the compounds, whose molecules (similarly as these investigated here) contain the carbazole skeleton, attract great attention over the past few years. Namely, materials based on them are very promising because of their great stability, good solubility, excellent photoconductive properties, relatively intense luminescence, and good performance in OFETs, OLEDs, and thermoelectric materials [42-52]. Moreover, these compounds, and particularly halogenated carbazoles, are important synthetic intermediates and pharmacological targets [53].

\section{Materials and methods}

Materials and crystal growth

3-Chloro- and 3-bromo-9-ethylcarbazole were obtained from Sigma-Aldrich and used without further purification.

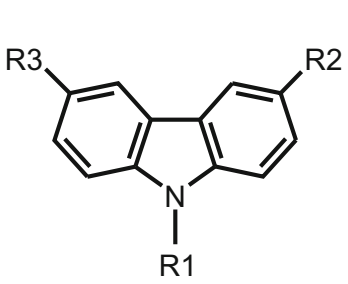

1) $\mathrm{R} 1=$ etyl, $\mathrm{R} 2=\mathrm{Cl}, \mathrm{R} 3=\mathrm{H}$

2) $\mathrm{R} 1=\mathrm{etyl}, \mathrm{R} 2=\mathrm{Br}, \mathrm{R} 3=\mathrm{H}$

3) $\mathrm{R} 1=$ etyl, R2 $=\mathrm{R} 3=\mathrm{Br}$ (DATJOY)

4) $\mathrm{R} 1=$ metyl, $\mathrm{R} 2=\mathrm{R} 3=\mathrm{Br}(\mathrm{MASCAL})$

5) $\mathrm{R} 1=\mathrm{H}, \mathrm{R} 2=\mathrm{Br}, \mathrm{R} 3=\mathrm{H}$ (MASCEP01)

6) $\mathrm{R} 1=\mathrm{H}, \mathrm{R} 2=\mathrm{R} 3=\mathrm{Br}$ (MASBUE)

7) $\mathrm{R} 1=\mathrm{H}, \mathrm{R} 2=\mathrm{R} 3=\mathrm{I}$ (YAYDUZ)

8) $\mathrm{R} 1=$ etyl, R2=R3=H (ETCABZ10)

9) $\mathrm{R} 1=$ metyl, R2=R3=H (NMCABZ)

10) $\mathrm{R} 1=\mathrm{R} 2=\mathrm{R} 3=\mathrm{H}(\mathrm{CRBZOLO3})$

Scheme 1 Structural formula of analyzed compounds 
Crystals of these compounds suitable for X-ray diffraction analysis were obtained by slow evaporation of a solution in o-xylene at a constant temperature of $279 \mathrm{~K}$.

X-ray crystal structure determination

The X-ray diffraction data for crystals of $\mathbf{1}$ and $\mathbf{2}$ were collected at 293(2) $\mathrm{K}$, using an XCALIBUR ${ }^{\mathrm{TM}_{3}} \mathrm{CCD}$ diffractometer with graphite-monochromated $\mathrm{Cu} \mathrm{K} \mathrm{K}_{\alpha}$ radiation. The structures were solved by direct methods and refined by full-matrix least-squares on $F^{2}$ using the SHELX-97 program package [54]. The non-hydrogen atoms were refined anisotropically. The hydrogen atoms were first localized in difference Fourier maps and next treated as riding atoms in geometrically idealized positions, with $\mathrm{C}-\mathrm{H}$ distances of 0.93 (aromatic), 0.96 (methyl), and $0.97 \AA \quad$ (methylene), and with $\operatorname{Uiso}(\mathrm{H})=1.2$ Ueq $\left(\mathrm{C}_{\text {aromatic, methyl }}\right)$ and $1.5 \mathrm{Ueq}\left(\mathrm{C}_{\text {methylene }}\right)$. Details of the crystallographic data and refinement parameters are summarized in Table 1 (full crystallographic data are contained in CCDC no. 1021254-1021255, and can be obtained free of charge at www.ccdc.cam.ac.uk/conts/retrieving.html or from the Cambridge Crystallographic Data Centre).
Hirshfeld surface analysis

In order to visualize and analyze the intermolecular interactions in the crystal structures of compounds $\mathbf{1}$ and $\mathbf{2}$ and also of their simple analogs (compounds 3-10), the CrystalExplorer 3.1 program [55] was used. It has enabled us to construct the threedimensional Hirshfeld surfaces (HSs) of molecules in crystals [56], which illustrate the interatomic contacts with distances equal to the sum of the van der Waals radii (represented as white) and with distances shorter (red) and longer (blue) than the values of this sum. Moreover, this program was used to obtain the fingerprint plots (FPs) [57], which are the two-dimensional representations of these surfaces, and are generated based on the $d_{e}$ and $d_{i}$ distances ( $d_{e}$ and $d_{i}$ are the distances from the HS to the nearest atom outside and inside the surface, respectively).

\section{Results and discussion}

Molecular and crystal structure

Compounds $\mathbf{1}$ and $\mathbf{2}$ crystallize in the same orthorhombic space group $\mathrm{Pbca}$ with one symmetry-independent
Table 1 Crystallographic data and refinement parameters

\begin{tabular}{|c|c|c|}
\hline Compound & 1 & 2 \\
\hline Chemical formula & $\mathrm{C}_{12} \mathrm{H}_{14} \mathrm{NCl}$ & $\mathrm{C}_{12} \mathrm{H}_{14} \mathrm{NBr}$ \\
\hline$M_{r}$ & 229.70 & 274.16 \\
\hline Crystal system, space group & Orthorhombic, $\mathrm{Pbca}$ & Orthorhombic, $P b c a$ \\
\hline Temperature (K) & $293(2)$ & 293(2) \\
\hline$a(\AA), b(\AA), c(\AA)$ & $\begin{array}{l}15.2301(3), 7.7277(2) \\
19.7598(5)\end{array}$ & $\begin{array}{l}15.2623(8), 7.7162(4), \\
20.2049(9)\end{array}$ \\
\hline$V\left(\AA^{3}\right)$ & $2325.60(10)$ & $2379.5(2)$ \\
\hline$Z$ & 8 & 8 \\
\hline$D_{\text {calc }}\left(\mathrm{g} / \mathrm{cm}^{3}\right)$ & 1.312 & 1.531 \\
\hline Radiation type & $\mathrm{Cu} \mathrm{K} \alpha$ & $\mathrm{Cu} \mathrm{K} \alpha$ \\
\hline$\mu\left(\mathrm{mm}^{-1}\right)$ & 2.64 & 4.45 \\
\hline Crystal size (mm) & $0.33 \times 0.14 \times 0.12$ & $0.47 \times 0.18 \times 0.17$ \\
\hline Diffractometer & Xcalibur Sapphire 3 & Xcalibur Sapphire 3 \\
\hline Absorption correction & multi-scan & multi-scan \\
\hline$T_{\min }, T_{\max }$ & $0.485,1.000$ & $0.403,1.000$ \\
\hline $\begin{array}{l}\text { No. of measured, independent and observed } \\
\quad(I>2 \sigma(I)) \text { reflections }\end{array}$ & $18396,2088,1893$ & $24027,2138,1983$ \\
\hline$\theta_{\min }, \theta_{\max }$ & $4.48,67.41$ & $5.25,67.54$ \\
\hline$h$ & -1418 & -1817 \\
\hline$k$ & -99 & -99 \\
\hline$l$ & -2323 & -2424 \\
\hline$R_{i n t}$ & 0.039 & 0.033 \\
\hline$(\sin \theta / \lambda)_{\max }\left(\AA^{-1}\right)$ & 0.599 & 0.599 \\
\hline$R\left(F^{2}>2 \sigma\left(F^{2}\right)\right), w R\left(F^{2}\right), S$ & $0.043,0.131,1.09$ & $0.045,0.114,1.02$ \\
\hline No. of reflections/parameters & $2088 / 146$ & $2138 / 146$ \\
\hline$\Delta \rho_{\max }, \Delta \rho_{\min }\left(\mathrm{e}^{-3}\right)$ & $0.18,-0.37$ & $0.84,-0.70$ \\
\hline
\end{tabular}


molecule (Fig. 1a, b) in the asymmetric parts of the unit cells of similar dimensions (Table 1). The values of the unit-cell similarity index $(\Pi)$ [58] and the isostructurality index [59] $\left(I_{i}(n) ; n\right.$ denote a number of identical heavy atoms in the related structures, and here it is equal 13) calculated for these two compounds are 0.016 and $98.8 \%$, respectively. These values are very close to the values of 0.000 and $100 \%$, respectively, and as such indicate that structures $\mathbf{1}$ and $\mathbf{2}$ are close to the ideal case of isostructurality. The geometric parameters of molecules of two these compounds are similar; the corresponding bond lengths are the same within $3 \sigma$ and the bond angles differ by less than $1^{\circ}$. The bond lengths within carbazole skeletons of these molecules are in a good agreement with the corresponding distances in the unsubstituted carbazole [41], and the exceptions here are the lengths of the $\mathrm{C} 2-\mathrm{C} 3$ (in 1) and $\mathrm{C} 2-\mathrm{C} 3$ and $\mathrm{C} 6-\mathrm{C} 7$ (in 2) bonds; they are shorter by 0.017 (C2-C3 and $\mathrm{C} 6-\mathrm{C} 7$ in $\mathbf{1}$ and $\mathbf{2}$, respectively) and $0.019 \AA$ than the corresponding distances in carbazole. As can be expected the carbazole skeleton in each of $\mathbf{1}$ and $\mathbf{2}$ is planar, with the largest out-of-plane deviations being
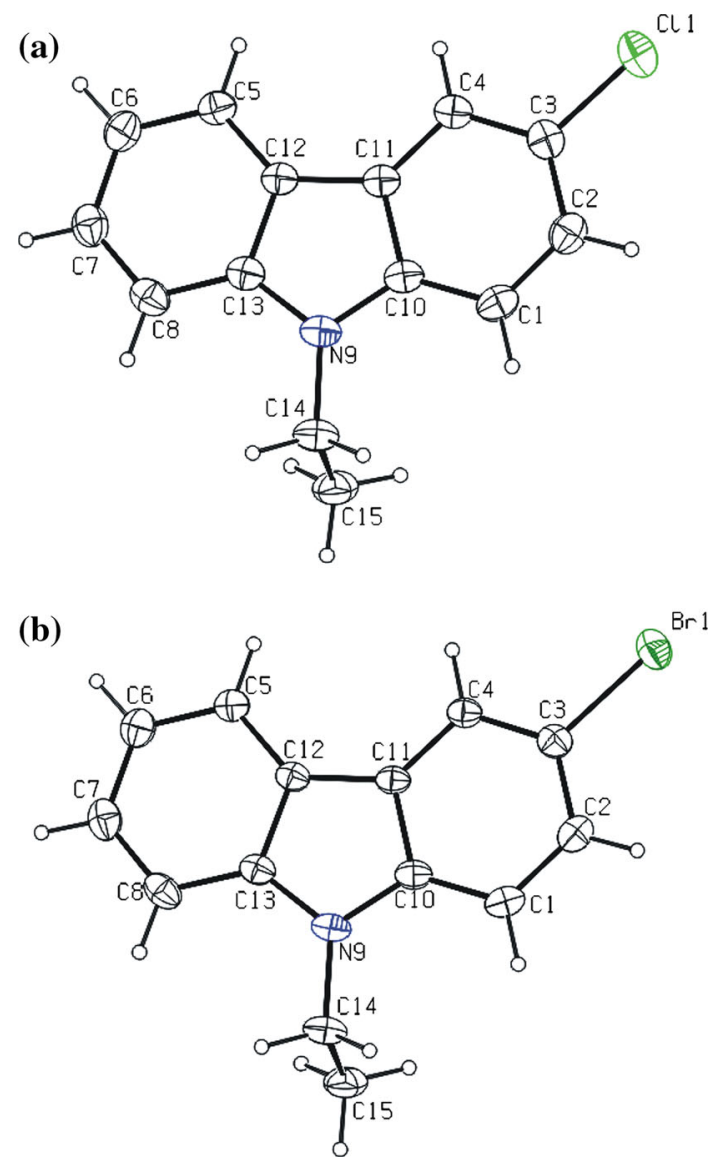

Fig. 1 Views of the molecules of $\mathbf{1}$ (a) and $\mathbf{2}$ (b), showing the atomnumbering schemes. Displacement ellipsoids are drawn at the $50 \%$ probability level and $\mathrm{H}$ atoms are shown as small spheres of arbitrary radii
0.047(2) and 0.033(3) $\AA$ for atoms C7 and C12, respectively. The halogen and ethyl $\mathrm{C} 14$ atoms are practically coplanar with the planes of carbazole skeletons (the Cl1 and $\mathrm{Br} 1$ atoms deviate from these planes by only $0.025(2)$ and $-0.016(1) \AA$, respectively, and $\mathrm{C} 14$ atoms deviate by $0.135(3)$ and $0.136(4) \AA$ ), while the $\mathrm{C} 15$ atoms of ethyl substituents lie 1.576(4) and 1.567(4) $\AA$ below the planes formed by atoms of carbazole skeletons of $\mathbf{1}$ and $\mathbf{2}$, respectively. The angles between these planes and C14-

Table 2 Hydrogen bond geometry $\left(\AA{ }^{\circ}\right)$

\begin{tabular}{llllll}
\hline $\mathrm{D}-\mathrm{H} \cdots \mathrm{A}$ & Compound & $\mathrm{D}-\mathrm{H}$ & $\mathrm{H} \cdots \mathrm{A}$ & $\mathrm{D} \cdots \mathrm{A}$ & $\mathrm{D}-\mathrm{H} \cdots \mathrm{A}$ \\
\hline $\mathrm{C} 5-\mathrm{H} 5 \cdots \mathrm{Cg} 1^{(\mathrm{i})}$ & 1 & 0.93 & 2.76 & $3.586(2)$ & 149 \\
& $\mathbf{2}$ & 0.93 & 2.77 & $3.596(3)$ & 149 \\
\hline
\end{tabular}

Symmetry code (i) $-\mathrm{x},-112+\mathrm{y}, 112-\mathrm{z}$
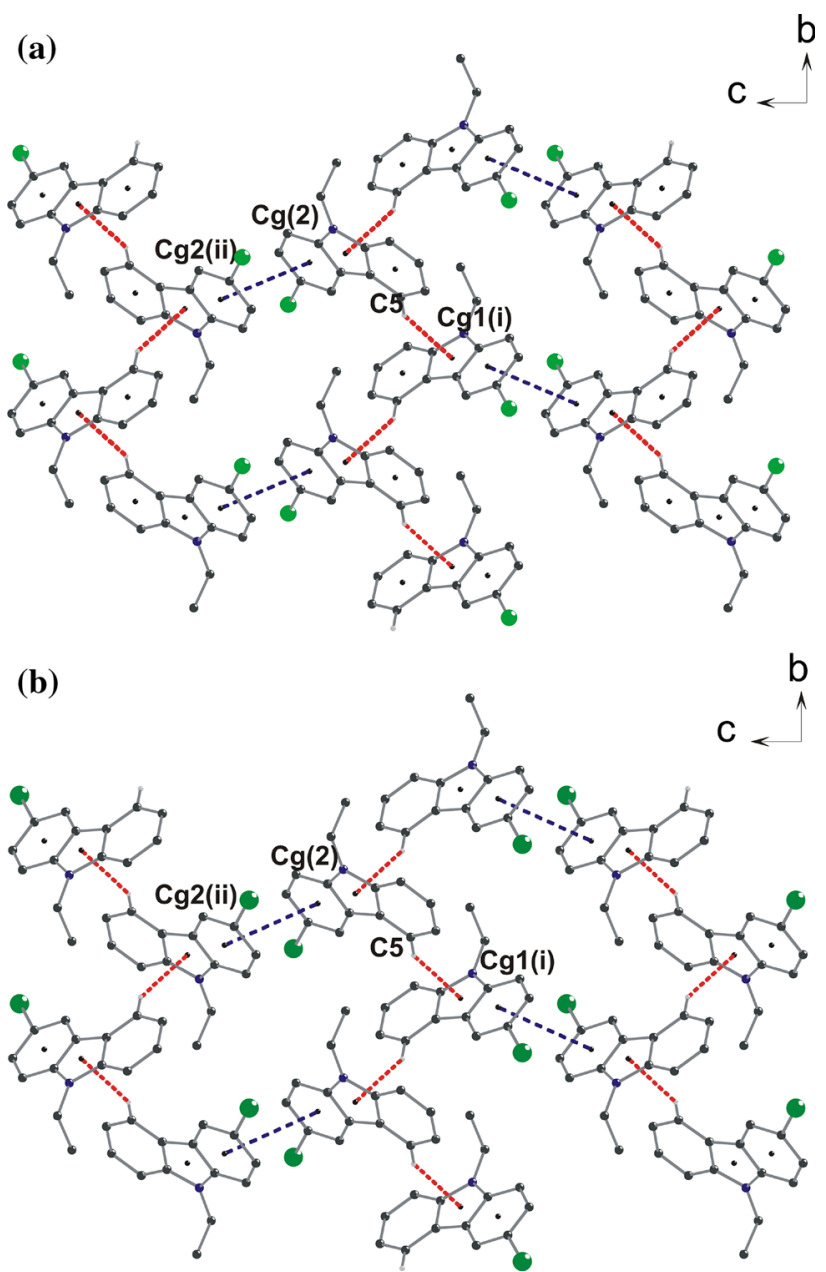

Fig. 2 Parts of the crystal structures of $\mathbf{1}$ (a) and $\mathbf{2}$ (b) showing the sheets parallel to the (100) plane formed by $\mathrm{C}-\mathrm{H} \cdots \pi$ hydrogen bond (thick dashed red lines) linking the molecules into the chains parallel to the crystallographic $b$ axis, and slipped face-to-face $\pi \cdots \pi$ interaction (thick dashed blue lines). All $\mathrm{H}$ atoms not involved in the $\mathrm{C}-\mathrm{H} \cdots \pi$ interactions have been omitted for clarity. The centroids of rings are denoted by small black circles (Color figure online) 

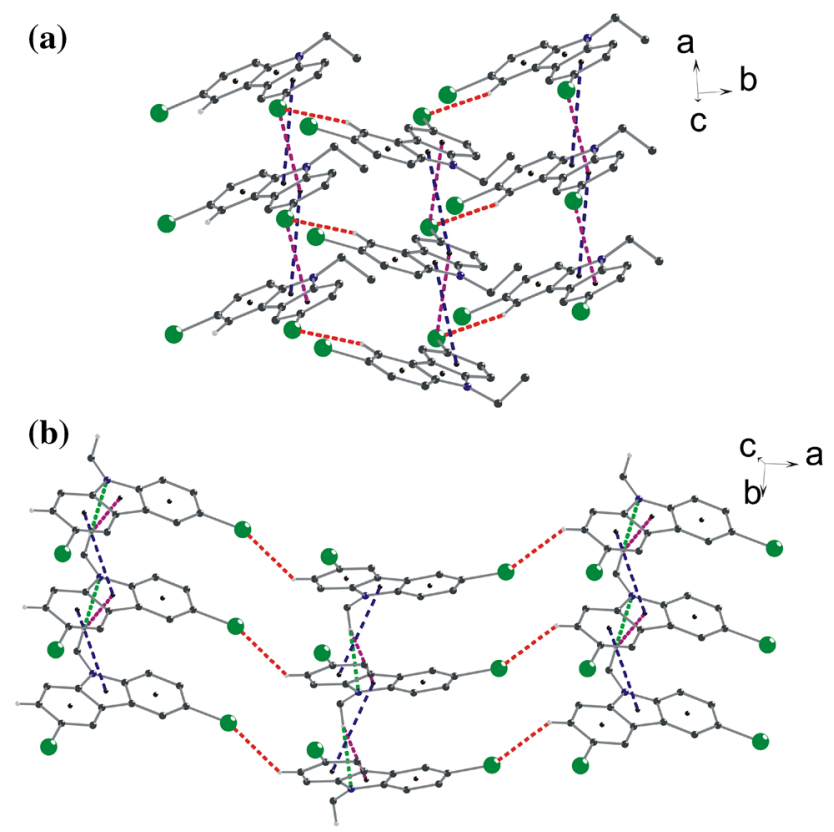

(c)

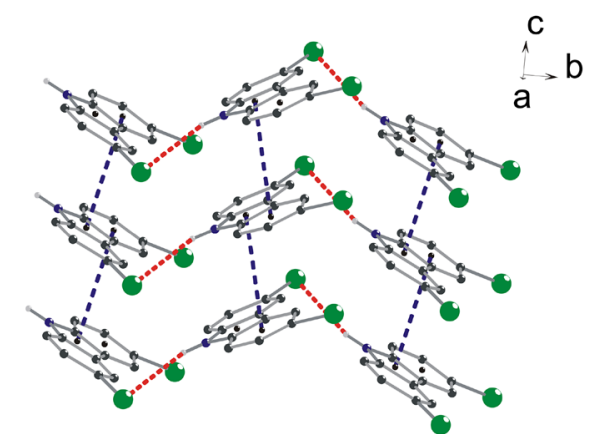

Fig. 3 Parts of the crystal structures of three simple analogs of $\mathbf{1}$ and 2, i.e., DATJOY (a), MASCAL (b), and MASBUE (c), showing slipped face-to-face $\pi \cdots \pi$ interactions (dashed blue lines) linking molecules into the stacks parallel to the shortest crystallographic axes and interstack $\mathrm{D}-\mathrm{H} \cdots \mathrm{Br}(\mathrm{D}=\mathrm{C}$ or $\mathrm{N})$ hydrogen bonds (dashed red lines), which together form the $2 \mathrm{D}$ sheets, and also additional intrastack $\mathrm{C}-\mathrm{X} \cdots \pi(\mathrm{X}=\mathrm{H}$ or $\mathrm{Br}$, pink dashed lines $)$ and $\mathrm{C}-\mathrm{H} \cdots \mathrm{N}$ (green dashed lines) interactions. All $\mathrm{H}$ atoms not involved in these interactions have been omitted for clarity. The ring centroids are denoted by small black circles (Color figure online)

C15 bonds are 73.7(2) and 73.2(2) ${ }^{\circ}$, respectively. The C3$\mathrm{Cl} 1$ and $\mathrm{C} 3-\mathrm{Br} 1$ bond lengths $[1.747(2)$ and 1.906(4) $\AA$, respectively] in these compounds are in close agreement with the averages of 10,565 and 10,466 values, i.e., 1.741(23) and 1.899(22) А, respectively, retrieved from the CSD by MOGUL [60] for the groups of compounds containing $\mathrm{Cl}$ or $\mathrm{Br}$ substituent attached to the benzene ring.

In the case of compounds $\mathbf{1}$ and $\mathbf{2}$, similarities exist not only at the molecular level but also at the level of the molecular packing. These compounds exhibit identical patterns of intermolecular interactions, with similar dimensions for one symmetry-independent non-conventional weak $\mathrm{C}-\mathrm{H} \cdots \pi$ hydrogen bond (Table 2) and the slipped face-to-face $\pi \cdots \pi$ interaction in the two compounds. In the crystal structure of each of them, the aromatic $\mathrm{C} 5$ atom in the molecule at $(\mathrm{x}, \mathrm{y}, \mathrm{z})$ acts as a hydrogen bond donor, via atom $\mathrm{H} 5$, to the central fivemembered ring (centroid $\mathrm{Cg} 1$ ) of carbazole skeleton of the molecule at $(-\mathrm{x},-1 / 2+\mathrm{y}, 1 / 2-\mathrm{z})$, thus forming a chain running parallel to the shortest crystallographic axis, i.e., the $b$ axis (Fig. 2a, b). The molecules, belonging to the adjacent chains and related by translation along $c$ axis, are further connected by the slipped face-to-face $\pi \cdots \pi$ interaction involving the terminal $\mathrm{C} 1-\mathrm{C} 2-\mathrm{C} 3-\mathrm{C} 4-\mathrm{C} 11-\mathrm{C} 10$ benzene rings (centroids $\mathrm{Cg} 2$ ). In crystals of $\mathbf{1}$ and $\mathbf{2}$, the perpendicular distances of the ring centroids $\mathrm{Cg} 2$ from the planes containing the symmetry-related centroids $\mathrm{Cg} 2$ at $(-\mathrm{x},-\mathrm{y}, 1-\mathrm{z})$ are 3.396(1) and 3.422(1) $\AA$, respectively, while the centroid-to-centroid separations are 3.810(1) and 3.947 (2) $\AA$ and the slippages are 1.726 and $1.968 \AA$, respectively. The planes of these rings are parallel, making the angles of only $0.00(7)$ and $0.0(1)^{\circ}$, respectively. In each of these compounds, this interaction connects two molecules into a dimer centered at $(0.5,0.5,0.5)$, and a combination of the two types of interactions generates a twodimensional (2D) framework in the form of a sheet parallel to (100). Moreover, in the crystal structures of $\mathbf{1}$ and $\mathbf{2}$, despite the presence of halogen (X) atoms as substituents at position 3, there are no halogen bonds, close contacts between halogen atoms (the shortest $\mathrm{Cl} \cdots \mathrm{Cl}$ and $\mathrm{Br} \cdots \mathrm{Br}$ distances are 4.024 and $4.031 \AA$, respectively), nor nonconventional $\mathrm{C}-\mathrm{H} \cdots \mathrm{X}$ hydrogen bonds.

Although the formation of a continuous 2D-framework is a common characteristic of the crystal packing in $\mathbf{1}$ and $\mathbf{2}$ and in their simple analogs, which are the carbazole derivatives possessing two bromine substituents attached to its skeleton at positions 3 and 6 (i.e., 6), and additionally ethyl (i.e., 3) or methyl (i.e., 4) groups as substituents at position 9 (these compounds crystallize with $Z^{\prime}=1$ in the $P 2{ }_{1}$ and $P c a 2_{1}$ space groups, respectively), the presence of additional $\mathrm{Br}$ atom at position 6 results in an appearance of the single

$\mathrm{C}-\mathrm{H} \cdots \mathrm{Br}$ (in 3 and 4) and $\mathrm{N}-\mathrm{H} \cdots \mathrm{Br}$ (in 6) hydrogen bonds. These interactions connect the molecules (related by $2_{1}$ screw axes) of each of these compounds, into the simple $\mathrm{C}(7)$ (in $\mathbf{6}$ and 3) or C(8) (in 4) chains (Fig. 3a-c). Similar to $\mathbf{1}$ and $\mathbf{2}$, in the crystal structures of $\mathbf{3}, \mathbf{4}$, and $\mathbf{6}$ there are also the slipped face-to-face $\pi \cdots \pi$ interactions, but in contrast to them, there are no dimers and these interactions link molecules into the stacks parallel to the shortest crystallographic axes. It is also noteworthy that the molecular stacks are connected by the $\mathrm{C}-\mathrm{Br} \cdots \pi$ interaction in 3 , while in 4 by the non-conventional $\mathrm{C}-\mathrm{H} \cdots \mathrm{N}$ and $\mathrm{C}-$ $\mathrm{H} \cdots \pi$ hydrogen bonds, in which the carbon atom of terminal methyl group acts as a hydrogen bond donor. 
Fig. 4 Parts of the crystal structures of five simple analogs of $\mathbf{1}$ and 2, i.e., MASCEP01 (a), YAYDUZ (b), ETCABZ (c), NMCABZ (f), and CRBZOL03 (g), showing the molecular packing stabilized mainly by $\mathrm{C}-\mathrm{H} \cdots \pi$ interactions (dashed pink lines), and additionally by $\mathrm{N}-\mathrm{H} \cdots \pi$ (dashed blue lines in $\mathbf{a}$ and $\mathbf{e})$ or $\mathrm{C}-\mathrm{I} \cdots \pi$ (dashed orange lines in $\mathbf{b})$. All $\mathrm{H}$ atoms not involved in these interactions have been omitted for clarity. The ring centroids are denoted by small black circles (Color figure online)
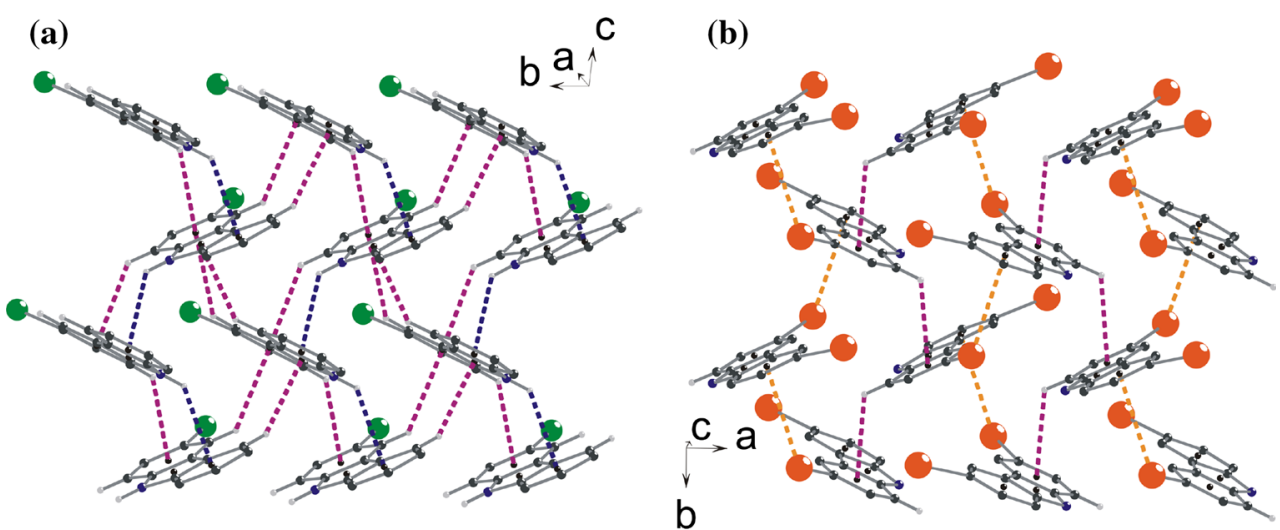

(c)

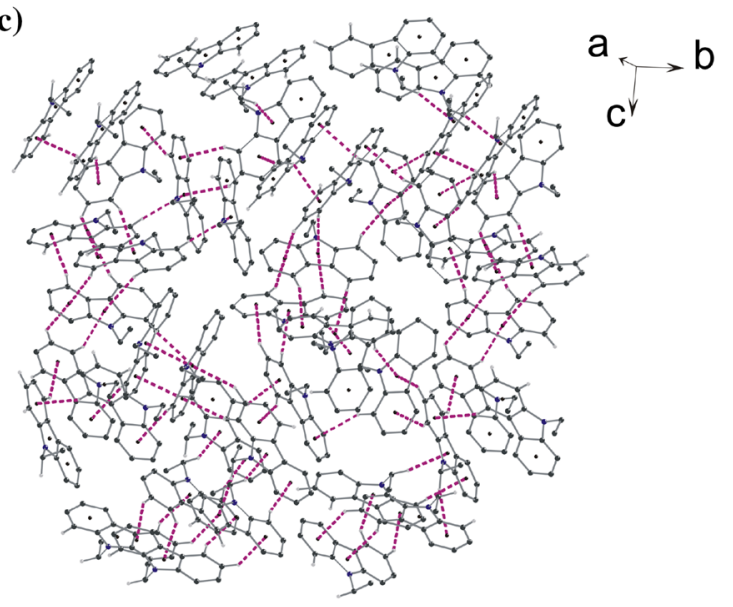

(d)

(e)

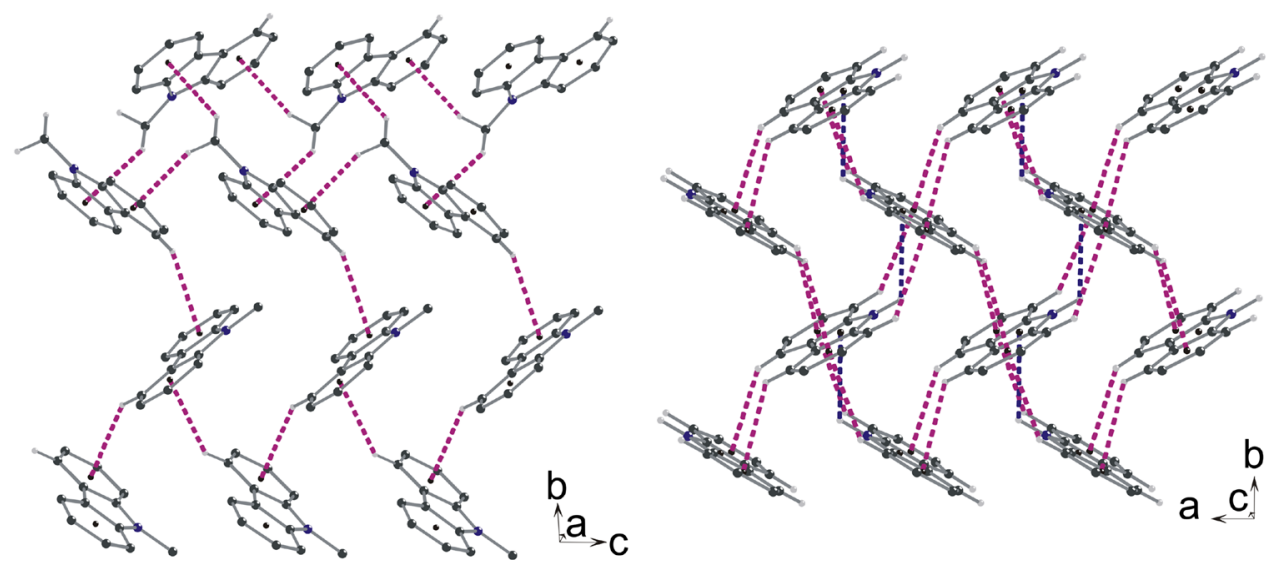

By contrast to 1-4 and 6, in the structures of monosubstituted bromine derivative of carbazole (5) and its diiodo-substituted derivative (7), crystallizing with $Z^{\prime}=1$ in the space groups $P{ }_{1} / c$ and $P b c a$, respectively, and similarly as in unsubstituted carbazole $\left(\mathbf{1 0} ; Z^{\prime}=0.5\right.$ in the Pbnm space group), its methyl $\left(\mathbf{9} ; Z^{\prime}=1\right.$ in the $P 2{ }_{1} / b$ space group) and ethyl (8; $Z^{\prime}=5$ in the $P b c a$ space group) derivatives, there are no slipped $\pi \cdots \pi$ interactions (Fig. $4 a-$ e). A molecular packing in all these compounds is stabilized mainly by $\mathrm{C}-\mathrm{H} \cdots \pi$ weak hydrogen bonds (three, one, four, sixteen and two in $\mathbf{5}, \mathbf{7}, \mathbf{9}, \mathbf{8}$, and $\mathbf{1 0}$, respectively), and also by one and three $\mathrm{N}-\mathrm{H} \cdots \pi$ hydrogen bonds in $\mathbf{5}$ and 10, while in $\mathbf{7}$ by the $\mathrm{C}-\mathrm{I} \cdots \pi$ interaction. Together, these interactions generate the $2 \mathrm{D}$ sheets perpendicular to the longest crystallographic axes.

In summary, of the ten carbazoles analyzed here, in the crystal structures of five (i.e., of compounds 1-4 and 6) there are slipped $\pi \cdots \pi$ interactions, and additionally in the 
Fig. 5 Packing of molecules in the crystal structures of $\mathbf{1}$ (a), $\mathbf{2}$ (b), 3 (c), 4 (d), and 6 (e). Molecules are drawn with a space-filling model for planar moieties, and a ball-and-stick model for the substituents at the 9-position of carbazole skeleton. All aromatic $\mathrm{H}$ atoms have been omitted for clarity. The values of $d[\pi$-stacking distance, i.e., the shortest distance between the planes of anthracene moieties belonging to the two adjacent molecules (M)], P, R, $\mathrm{dp}, \mathrm{dr}, \mathrm{d}_{\pi}, \mathrm{d}_{\mathrm{H}}, \delta_{\mathrm{H}}$, and $\mathrm{AO}$ are given

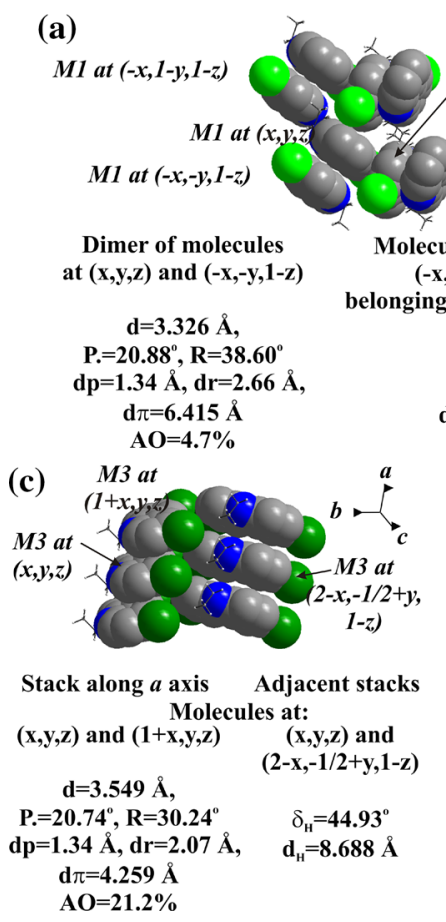

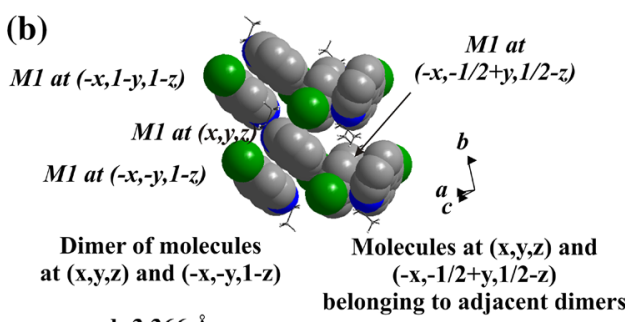

$\mathrm{d}=3.366 \AA$,

$P .=26.16^{\circ}, R=37.14^{\circ}$

$\mathrm{dp}=1.65 \AA, \mathrm{dr}=2.55 \AA, \quad \delta_{\mathrm{H}}=80.16^{\circ}$ d $\pi=6.938 \AA$

$\mathrm{d}_{\mathrm{H}}=\mathbf{5 . 4 5 3 \AA}$

M6 at $(x, y,-1+a)$

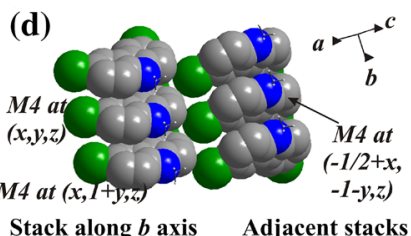

Stack along $b$ axis Adjacent stacks Stack along $c$ axis Adjacen
Molecules at:

$(\mathbf{x}, \mathbf{y}, \mathbf{z})$ and $(\mathbf{x}, 1+y, z) \quad(x, y, z)$ and $\quad(x, y, z)$ and $(x, y,-1+z) \quad(x, y, z)$ and

$\mathrm{d}=3.653 \AA$,

$P=14.87^{\circ}, R=27.81^{\circ}$ $(-1 / 2+x,-1-y, z)$

$\mathrm{d}=3.527 \AA$,

$\delta_{\mathrm{H}}=\mathbf{5 7 . 4 9 ^ { \circ }} \quad \mathbf{P}=\mathbf{1 0 . 6 4}^{\circ}, \mathbf{R}=\mathbf{2 8 . 0 0 ^ { \circ }} \quad \delta_{\mathrm{H}}=\mathbf{5 3 . 3 6 ^ { \circ }}$

$=0.97 \AA, d r=1.93 \AA, \quad d_{H}=11.390 \AA \quad d p=0.66 \AA, d r=1.88 \AA, \quad d_{H}=4.922 \AA$

$\mathrm{d} \pi=4.073 \AA$

$\mathrm{AO}=\mathbf{2 7 . 2 \%}$ $\mathrm{d} \pi=3.995 \AA$

$\mathrm{AO}=\mathbf{3 0 . 5} \%$ case of three of them, i.e., $\mathbf{3}, \mathbf{4}$, and $\mathbf{6}$, a parallel arrangement of carbazole skeletons in the stacks running along the shortest crystallographic axes of length ca. $4 \AA$ is observed. In order to estimate the $\mathrm{AO}$ of adjacent $\pi$-stacking molecules of these five compounds, the phenomenological approach proposed by Curtis et al. [13], in combination with a simple model introduced by Janzen et al. [12], was used by us, and the values of estimated parameters such as the pitch $(P)$ and roll $(R)$ angles, the pitch $(d p)$ and roll $(d r)$ distances, the distance between the planes of carbazole skeletons $(d)$ and the value of $A O$, are given in Fig. 5 illustrating the packing molecules in the $2 \mathrm{D}$ layers. The values of structural parameters estimated according to Giershner and Park [61] for the slipped face-to-face (or $\pi$ stack) and HB arrangements, i.e., parameters such as the nearest neighbor distances for $\pi$-stacked $\left(d_{\pi}\right)$ and herringbone $\left(d_{H}\right)$ neighbors and the angle between planes of carbazole skeletons [(so-called "herringbone angle" $\left(\delta_{H}\right)$ ], are also given in this figure. Analysis of these data shows that for carbazoles with two $\mathrm{Br}$ substituents (i.e., 3, 4, and $\mathbf{6}$ ), the values of $P$ parameters are smaller than the values of $R$ parameters. Although on the basis of a criterion proposed by Curtis et al. $(d r>d p)$, the molecular packing could be specified here as a typical HB arrangement, the roll angles smaller than $45^{\circ}$ and the $d_{H}$ distances larger than the $d_{\pi}$ distances indicate on the slipped face-to-face arrangement in 2D-layers of 3, 4, and $\mathbf{6}$. Moreover, the small $d p$ distances $(0.66-1.34 \AA$ ) and the $d r$ distances (1.88-2.07 $\AA$ ) smaller than the widths $(w)$ of the molecules provide some extent $\pi$-overlap. This fact is confirmed by the values of AO estimated for them, which are changed from $21.1 \%$ in $\mathbf{3}$, through $27.2 \%$ in $\mathbf{4}-30.5 \%$ in $\mathbf{6}$, i.e., in the order of a decreasing of the length of substituent attached to the $\mathrm{N}$ atom of carbazole skeleton. It is noteworthy that the presence of $\pi$-stacks with overlap between adjacent molecules is not a characteristic of the typical herringbone packing in 7 (i.e., in the simple analog of $\mathbf{6}$, in which atoms $\mathrm{Br}$ are replaced by the largest iodide atoms), where $d_{H}=4.922 \AA<d_{\pi}=5.802 \AA$ and $\delta_{H}=53.36^{\circ}$. The distances between nearest neighbors estimated for herringbone neighbors are smaller from these estimated for $\pi$ stacked neighbors also in the case of isostructural compounds $\mathbf{1}$ and $\mathbf{2}$, but in their crystal structures there is a motif of the slipped face-to-face dimer with slight (by contrast to 3, 4, and $\mathbf{6}$ ) spatial overlap between two molecules (4.7 and $7.1 \%$, respectively). Admittedly, the dimers are arranged in columns (Fig. 5a, b), but the significant displacements along two molecular axes and large distances between aromatic rings eliminate the $\pi \cdots \pi$ interactions between molecules of adjacent dimers, and the $d_{H}$ distance smaller than the $d_{\pi}$ distance can indicate on the sandwich herringbone-like packing. Thus, the molecular packing in mono-substituted halogen derivatives of ethylcarbazole (1 and $\mathbf{2})$ is intermediate between the slipped face-to-face arrangement in di-substituted bromine derivatives of this compound, methylcarbazole and carbazole (3, 4, and 6), and the typical herringbone packing in compounds such as di-substituted iodide derivative of 
Fig. 6 Hirshfeld surfaces for molecules of compounds $\mathbf{1}, \mathbf{2}, \mathbf{5}$, and 7-10, mapped with $d_{\text {norm }}$ distance
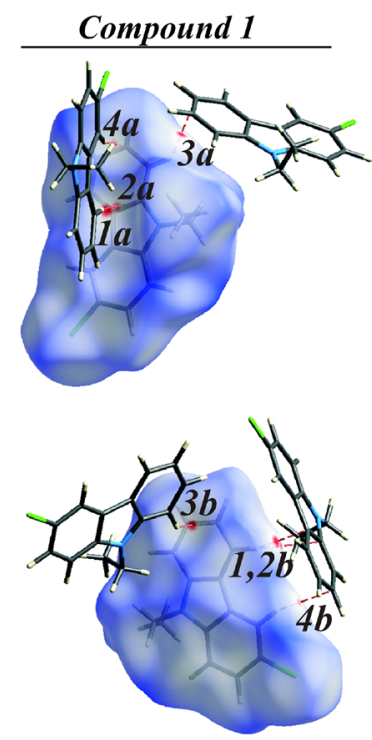

Compound 8
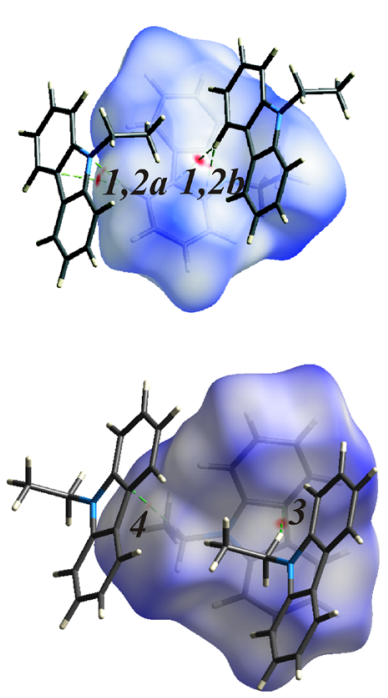

Compound 2
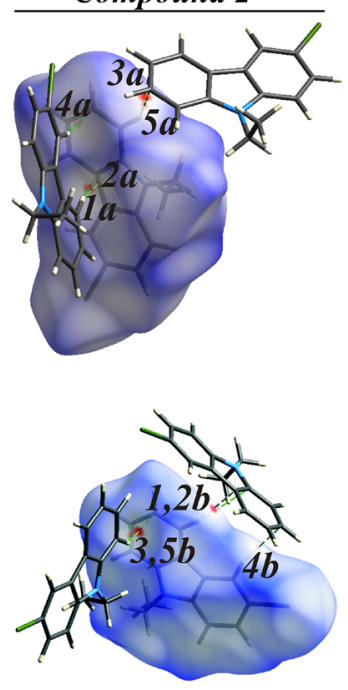

Compound 9
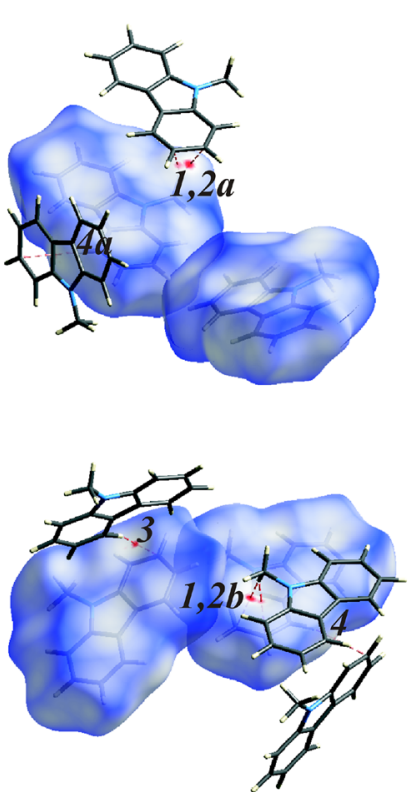

Compound 5

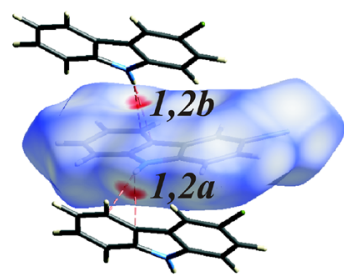

Compound 7

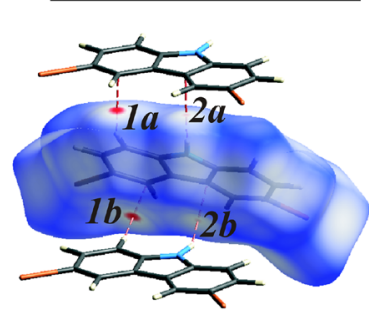

Compound 10
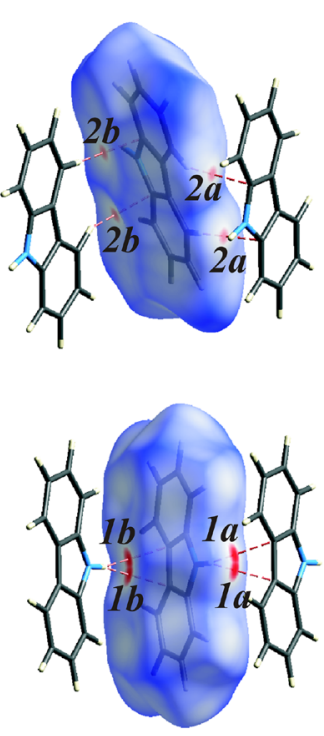

ethylcarbazole (7), mono-substituted bromine derivative of carbazole (5), carbazole (10), and its two alkyl derivatives (8 and 9).

\section{Hirshfeld surface}

The analysis of molecular three-dimensional HSs and twodimensional FPs obtained for the investigated compounds shows that the intermolecular $\mathrm{H} \cdots \mathrm{H}, \mathrm{C} \cdots \mathrm{H} / \mathrm{H} \cdots \mathrm{C}$, and $\mathrm{H} \cdots \mathrm{X} /$ $\mathrm{X} \cdot \mathrm{H}$ contacts have a major contributor in the crystal packings in 1, 2, 8, and 9, 10 and 5, and 3, 4, 6, and 7, respectively, comprising 43.4, 42,6, 59.6 (av), and 53.2 (av) $\%$ [in the case of 8 and 9 the average values (av) calculated for two and five independent molecules, respectively, are given], 49.9 and $45.8 \%$, and $33.3,37.1,37.3$, and $32.0 \%$ of the total HSs of their molecules, respectively. The structure of 7 is also dominated practically to the same extent by $\mathrm{C} \cdots \mathrm{H} / \mathrm{H} \cdots \mathrm{C}$ contacts which comprise $31.9 \%$ of the total Hirshfeld molecular surfaces, while their proportion in the structures of $\mathbf{9 , 8}, \mathbf{1}$, and $\mathbf{2}$ is, in a comparison with dominating $\mathrm{H} \cdots \mathrm{H}$ contacts, smaller but still significant $\left(45.0,38.2_{(\mathrm{av})}, 32.2\right.$ and $32.1 \%$, respectively). The shortest $\mathrm{C} \cdots \mathrm{H} / \mathrm{H} \cdots \mathrm{C}$ contacts, which reveal in the molecular HSs in the form of intense red areas (Fig. 6), correspond to the $\mathrm{C}-\mathrm{H} \cdots \pi$ [in $\mathbf{1}$ and $\mathbf{2}$ (spots $1 \mathrm{a}, \mathrm{b}-3 \mathrm{a}, \mathrm{b}$ ), $\mathbf{7}$ (spots 1a, b), 8 (spots 1a, b and 2a, b) and 9 (spots 1a, b, 2a, b and 3 and)] 
Fig. 7 Decomposed 2D fingerprint plots of $\mathrm{C} \cdots \mathrm{H} / \mathrm{H} \cdots \mathrm{C}$ contacts for compounds $\mathbf{1}, \mathbf{2}, \mathbf{5}$, and 7-10

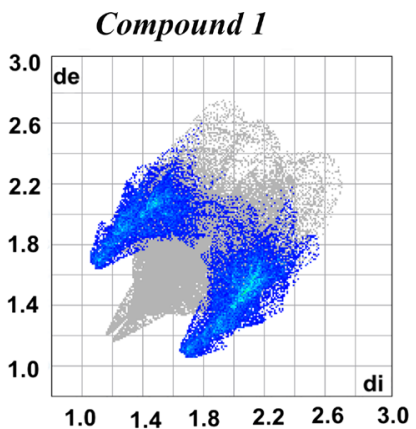

Compound 7

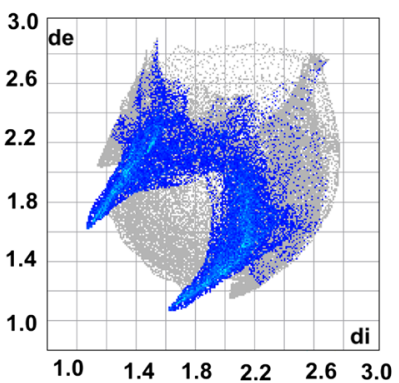

Compound 10

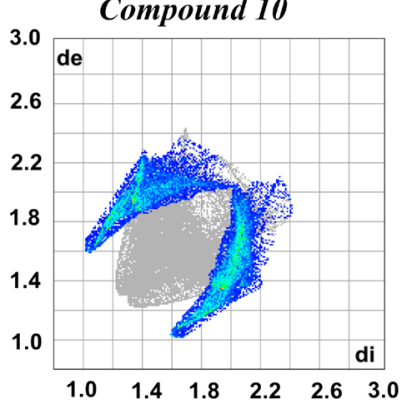

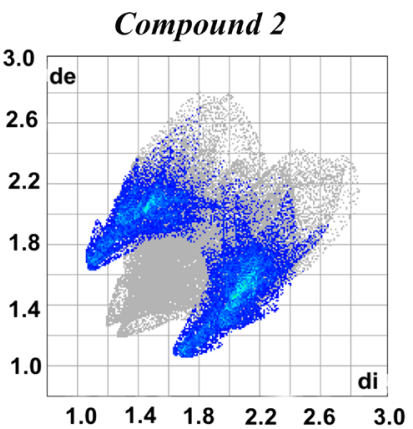

Compound 8
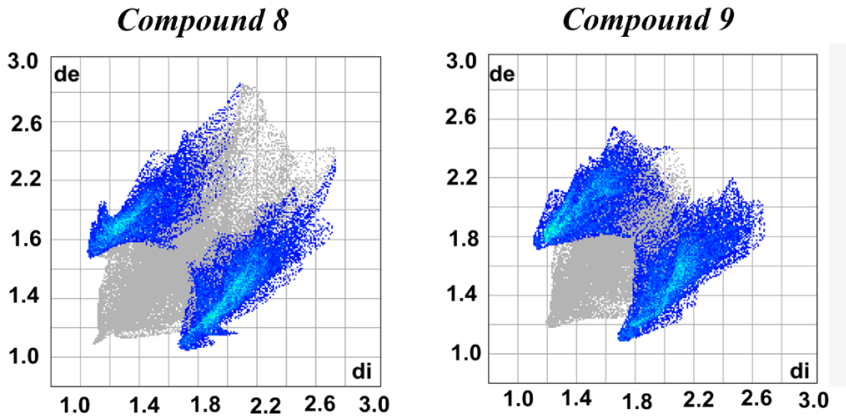

and $\mathrm{N}-\mathrm{H} \cdots \pi$ [in $\mathbf{5}$ (spots $1 \mathrm{a}, \mathrm{b}$ and $2 \mathrm{a}, \mathrm{b}$ ) and $\mathbf{1 0}$ (spots 1a, b)] hydrogen bonds. These interactions are represented in the 2D-FPs (Fig. 7) as the pronounced wings with the shortest $d_{i}+d_{e} \cong 2.7-2.8 \AA$ or ca $2.6 \AA$, respectively. In contrast to these compounds, the bright red areas on the molecular HSs of compounds 3 and 6 (Fig. 8) correspond to $\mathrm{H} \cdots \mathrm{Br} /$ $\mathrm{Br} \cdots \mathrm{H}$ contacts (spots $1 \mathrm{a}, \mathrm{b}$ ) and are associated with the presence of $\mathrm{C}-\mathrm{H} \cdots \mathrm{Br}$ and $\mathrm{N}-\mathrm{H} \cdots \mathrm{Br}$ hydrogen bonds, respectively, represented by two antennae in the bottom leftright (donor-acceptor) areas of the FPs (Fig. 9) at $d_{i}+$ $d_{e} \cong 2.8-2.9 \AA$. In turn, in the case of 4 , the most intense red spots correspond to $\mathrm{H} \cdots \mathrm{N} / \mathrm{N} \cdots \mathrm{H}$ contacts (spots $1 \mathrm{a}, \mathrm{b}$ in Fig. 8), which are associated with the $\mathrm{C}-\mathrm{H} \cdots \mathrm{N}$ hydrogen bonds and appear in the FPs also as two antennae at $d_{i}+-$ $d_{e} \cong 2.5 \AA$ (Fig. 10)

'In the case of compounds $\mathbf{3 , 4 , 5}$, and $\mathbf{6}$, next to contacts having the major contributor to the crystal packing, the interactions between $\mathrm{H}$ atoms play a significant role, comprising $32.9,27,1,27.7$, and $22.9 \%$ of the total HSs of their molecules. It is noteworthy that in the mono-substituted halogen derivatives of carbazoles (i.e., in 1, 2, and 5), the
$\mathrm{H} \cdots \mathrm{X} / \mathrm{X} \cdots \mathrm{H}$ contacts have also a significant share $(18.7,19.4$ and $16.5 \%$, respectively) in the crystal packing but it is about half smaller than in the di-substituted derivatives such as 3, 4, 6, and 7. Moreover, in the case of $\mathbf{1 , 2}$, and 5, in the FPs (Fig. 9), the $\mathrm{H} \cdots \mathrm{X} / \mathrm{X} \cdots \mathrm{H}$ contacts appear at the higher $d_{i}+d_{e}$ values equal ca 3.1-.2 $\AA$. Noteworthy here also the fact that in the crystals $\mathbf{3}, \mathbf{4}$, and $\mathbf{6}$, a fairly significant contributor (7.0, 9.7, and 10.8, respectively) have the contacts of C...C type, whose proportion in mono-substituted carbazole derivatives is significantly smaller, i.e., at the level of ca $2 \%$ in $\mathbf{1}$ and $\mathbf{2}$ and only $0.5 \%$ in $\mathbf{5}$. As it is illustrated in Fig. 11a, the contacts of this type are represented in FPs as the areas of pale blue/green color (in 3, $\mathbf{4}$ and $\mathbf{6}$ ) or as dark blue points (in 1 and 2) on the diagonals at around $d_{i}=d_{e} \cong 1.8 \AA$, and correspond to the presence of $\pi \cdots \pi$ stacking interactions in the crystal structures of these compounds. Moreover, they are also seen on the HSs mapped with shape index (Fig. 11b) as a pattern of red and blue triangles. It is worth adding that for all other compounds analyzed by us, the FPs and shape index surfaces do not contain such characteristic motifs for $\pi \cdots \pi$ stacking interactions. 
Fig. 8 Hirshfeld surfaces for molecules of compounds $\mathbf{3}, \mathbf{4}$, and $\mathbf{6}$, mapped with $d_{\text {norm }}$ distance

Fig. 9 Decomposed 2D fingerprint plots of $\mathrm{H} \cdots \mathrm{X} / \mathrm{X} \cdots \mathrm{H}$ contacts for compounds 1-6

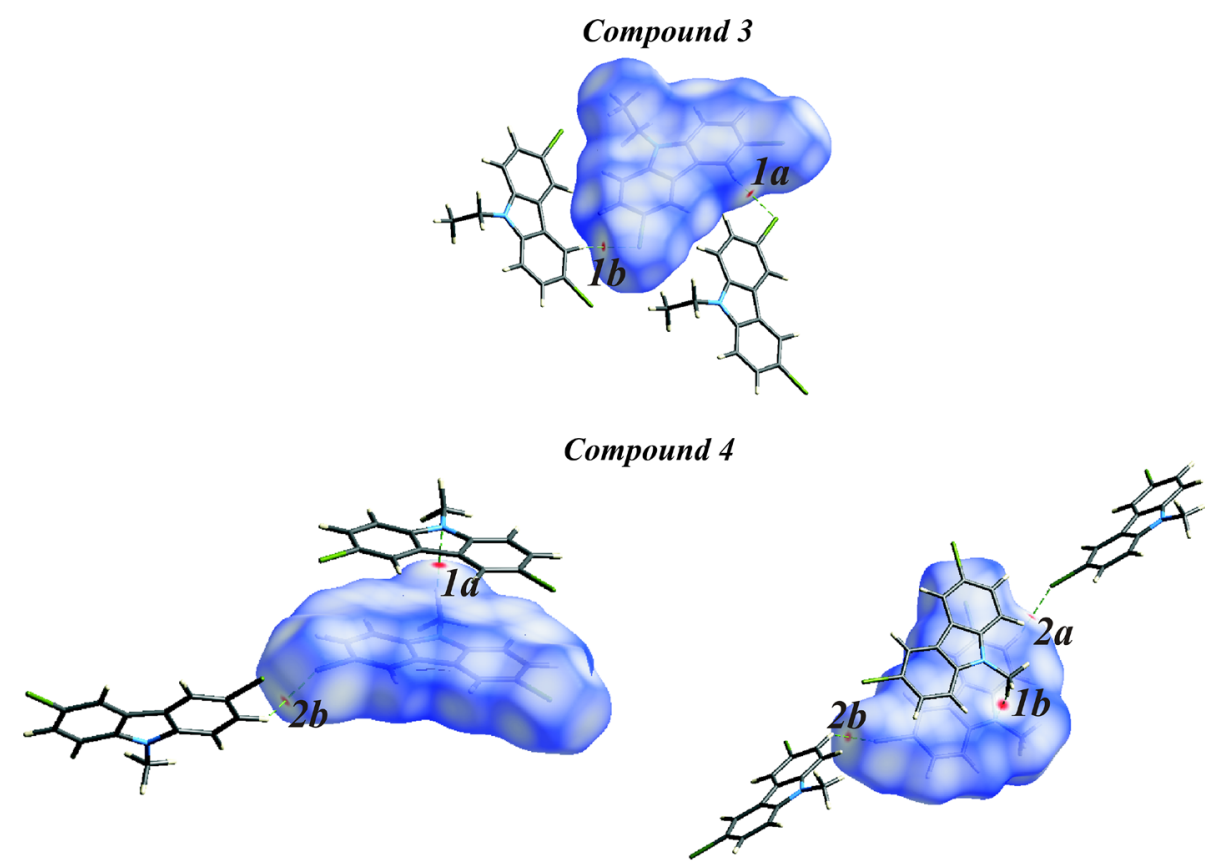

Compound 6
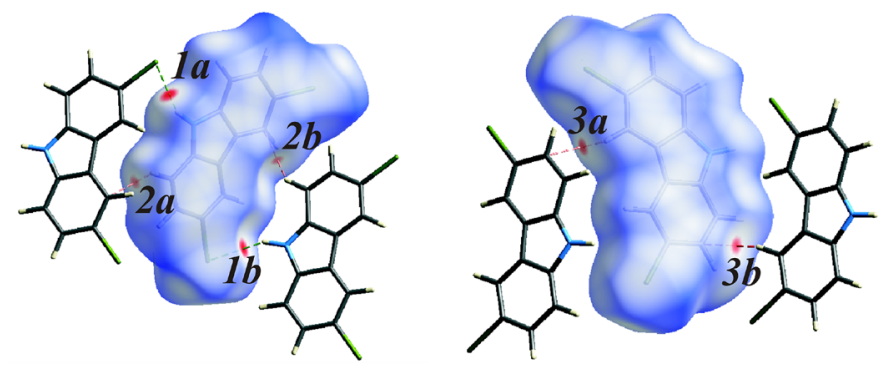
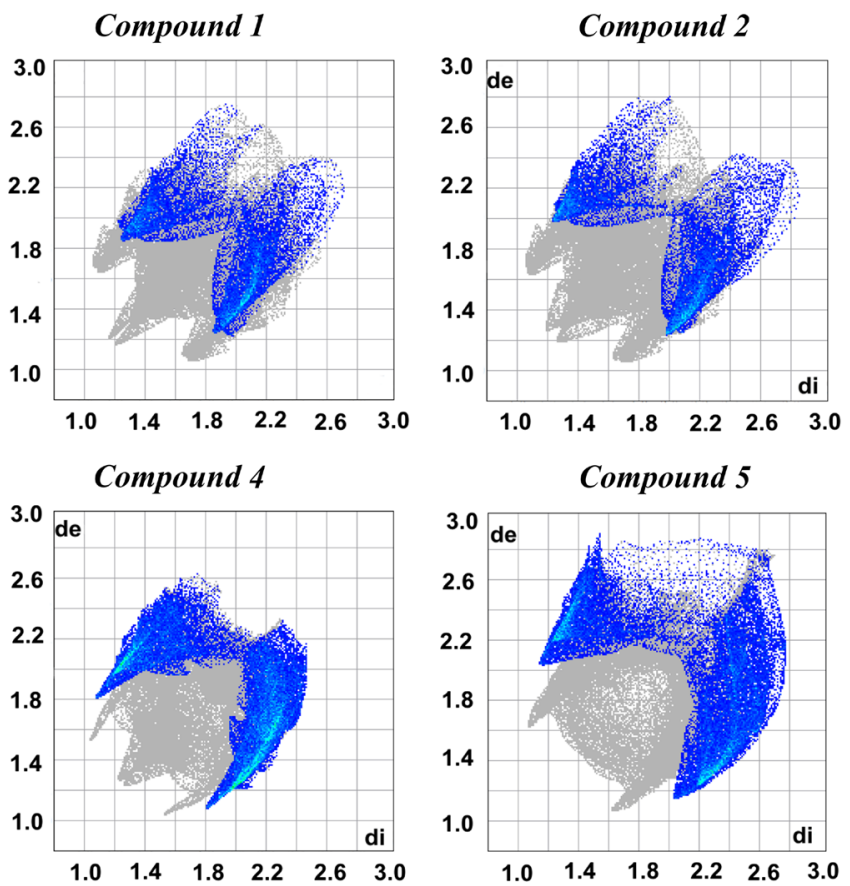

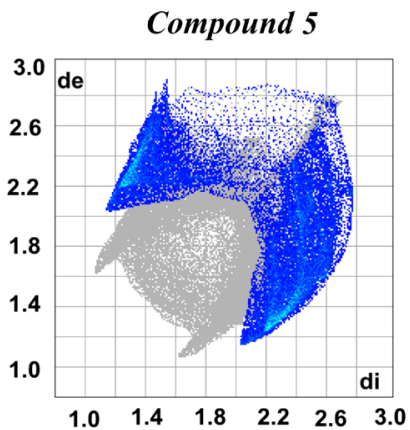

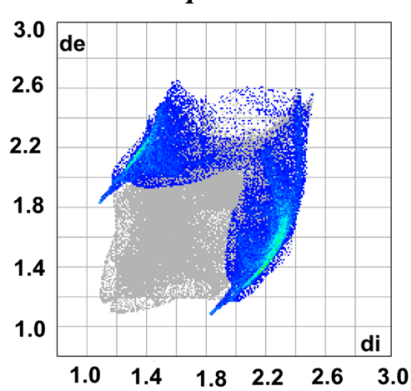

Compound 6

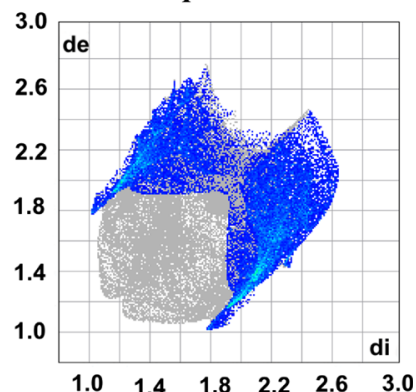




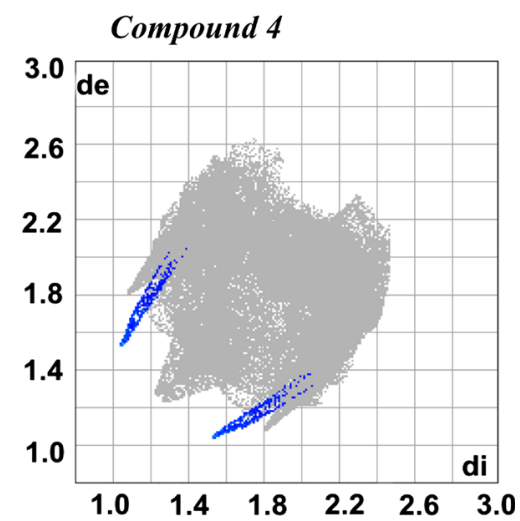

Fig. 10 Decomposed 2D fingerprint plots of $\mathrm{H} \cdots \mathrm{N} / \mathrm{N} \cdots \mathrm{H}$ contacts for compound 4

The inspection of other intermolecular contacts indicated also that there are no significant $\mathrm{X} \cdots \mathrm{X}$ interactions within the crystals of 1-7. In the case of $\mathbf{1}$ and $\mathbf{2}$ these contacts make only 0.5 and $0.7 \%$ of the surface area, respectively, and in $\mathbf{3}, \mathbf{4}, \mathbf{5}, \mathbf{6}$, and $\mathbf{7}$ their proportions are somewhat larger, i.e., 2.0, 2.6, 4.6, 4.1, and $4.1 \%$, respectively. Moreover, it was found that in the crystal structures of $\mathbf{1}, \mathbf{2}$, and $\mathbf{5}$, the intermolecular $\mathrm{C} \cdots \mathrm{X} / \mathrm{X} \cdots \mathrm{C}$ contacts are minimal $(0.4,1.1$, and $1.4 \%$, respectively), while in the structures of $\mathbf{3}, \mathbf{4}, \mathbf{6}$, and $\mathbf{7}$ the contacts of this type comprise $4.2,2.8,3.5 \%$ and as many as $9.2 \%$ of Hirshfeld molecular surfaces, respectively. It is noteworthy that there are no any contacts of type $\mathrm{N} \cdots \mathrm{X} / \mathrm{X} \cdots \mathrm{N}$ within the crystals of $\mathbf{3 - 5}$ or their contribution is negligible $(0.3-0.6 \%)$ in the crystals of $\mathbf{1}, \mathbf{2}, \mathbf{6}$, and $\mathbf{7}$. A similar situation is in the case of $\mathrm{C} \cdots \mathrm{N} / \mathrm{N} \cdots \mathrm{C}$ contacts, which do not occur in compounds $1,2,8$, and 10, and cover only $1.2,1.1,0.3,1.6,0.2_{(\mathrm{av})}$ and $0.2 \%$ of the HSs of molecules 3, 4, 5, 6, 9, and 10, respectively. Moreover, there are $\mathrm{N} \cdots \mathrm{N}$ contacts in none of the ten compounds analyzed here.

Analysis of the relative contribution of the different interactions to the molecular HSs of carbazole, ethylcarbazole, and their chloro- and bromo derivatives (Fig. 12) indicates that modification of the molecular structures of $\mathbf{8}$ and $\mathbf{1 0}$ by replacing one $\mathrm{H}$ atom at position 3 by halogen atom results first in appearance of $\mathrm{H} \cdots \mathrm{X} / \mathrm{X} \cdots \mathrm{H}$ and $\mathrm{C} \cdots \mathrm{C}$ contacts and a corresponding decrease of the proportion of $\mathrm{C} \cdots \mathrm{H} / \mathrm{H} \cdots \mathrm{C}$ and $\mathrm{H} \cdots \mathrm{H}$ (in 1, 2, and 5). A further modification consisting of the introduction of the second halogen atom in the position 6 leads to a significant increase of the proportion of $\mathrm{H} \cdots \mathrm{X} / \mathrm{X} \cdots \mathrm{H}$ and C...C contacts, accompanied by a decrease of contribution of $\mathrm{C} \cdots \mathrm{H} / \mathrm{H} \cdots \mathrm{C}$ and $\mathrm{H} \cdots \mathrm{H}$ interactions (in 3 and 6 ). What is interesting, the significant proportion of $\mathrm{C} \cdots \mathrm{C}$ contacts and simultaneous the low ratio of $(\% \mathrm{C} \cdots \mathrm{H}) /(\% \mathrm{C} \cdots \mathrm{C})$ interactions (both preferred from the viewpoint of the stacking molecular arrangement), which are typical for the crystal structures of 3,6-substituted halogen derivatives of carbazole and alkylcarbazoles [i.e., of compounds $\mathbf{3}, \mathbf{4}$, and $\mathbf{6}$, where the values of $(\% \mathrm{C} \cdots \mathrm{H}) /(\% \mathrm{C} \cdots \mathrm{C})$ are $2.7,1.9$ and 1.7 , respectively], do not occur when the halogen substituents are iodide atoms [i.e., in $7 ;(\% \mathrm{C} \cdots \mathrm{H}) /(\% \mathrm{C} \cdots \mathrm{C})=45.6]$.

Moreover, as can be seen from Fig. 8, in the crystal structures of compounds 8-10, the contribution of $\mathrm{H} \cdots \mathrm{H}$ contact increases with increasing of length of the substituent at position 9 of carbazole skeleton, while the contribution of $\mathrm{C} \cdots \mathrm{H} / \mathrm{H} \cdots \mathrm{C}$ contacts proportionally decreases. It is also noteworthy that in the case of compounds with two bromine substituents, i.e., $\mathbf{3}, \mathbf{4}$, and $\mathbf{6}$, the increasing of this length cause mainly the decrease of proportion of $\mathrm{C} \cdots \mathrm{C}$ contacts and the accompanying increase of ratio of $(\% \mathrm{C} \cdots \mathrm{H}) /(\% \mathrm{C} \cdots \mathrm{C})$ contacts.

\section{Conclusions}

The X-ray crystal structures of 3-chloro- and 3-bromo-9ethylcarbazole were described and compared with those of several of their simple analogs, including 9-ethylcarbazole, 9-methylcarbazole, unsubstituted carbazole and their mono- and di-substituted halogen derivatives. This comparison shows that modification of the molecular structure of the carbazole by replacing one of the $\mathrm{C}-\mathrm{H}$ and $\mathrm{N}-\mathrm{H}$ protons by $\mathrm{Cl}$ or $\mathrm{Br}$ atom and ethyl group, respectively, results in (i) an elimination of $\mathrm{N}-\mathrm{H} \cdots \pi_{(5-\text { membered ring), }} \mathrm{C} 1-$ $\mathrm{H} 1 \cdots \pi_{\text {(benzene ring) }}$ and $\mathrm{C} 4-\mathrm{H} 4 \cdots \pi_{\text {(benzene ring) }}$ interactions causing a typical herringbone arrangement of carbazole skeletons, (ii) associated with this a major decrease of proportion of $\mathrm{C} \cdots \mathrm{H} / \mathrm{H} \cdots \mathrm{C}$ contacts, and (iii) an appearance of the $\mathrm{H} \cdots \mathrm{X} / \mathrm{X} \cdots \mathrm{H}$ contacts and also $\mathrm{C} \cdots \mathrm{C}$ contacts corresponding to the slipped face-to-face $\pi \cdots \pi$ interactions linking molecules into dimers. The significant displacement along two molecular axes and too large distances between aromatic rings of molecules belonging to adjacent dimers, and also the presence of $\mathrm{C} 5-\mathrm{H} 5 \cdots \pi$ (5-membered ring) interaction, cause that $\pi \cdots \pi$ interactions between these dimers, are not, however, possible to achieve in the case of crystals of two isostructural compounds $\mathbf{1}$ and 2. Only further molecular modification relying on replacing the next $\mathrm{C}-\mathrm{H}$ proton (at position 6) by halogen atom causes not only elimination $\mathrm{C} 5-\mathrm{H} 5 \cdots \pi$ interaction present in the crystal structures of carbazole and its derivatives $\mathbf{1}$ and $\mathbf{2}$, but first of all the increase of contribution of C … C contacts and parallel arrangement of carbazole skeletons into stacks, which run along the shortest crystallographic axes and are stabilized mainly by slipped face-to-face $\pi \cdots \pi$ interactions.

Taking into account that the arrangement of molecules into the stacks is also characteristic for crystals of 3,6dibromo-9-methylcarbazole and 3,6-dibromocarbazole, and that in the crystal structures of alkylcarbazoles there is a 
Fig. 11 Decomposed 2D fingerprint plots of $\mathrm{C} \cdots \mathrm{C} \cdots$ contacts (a) and molecular Hirshfeld surfaces mapped with shape index (b) for compounds 1-4 and 6
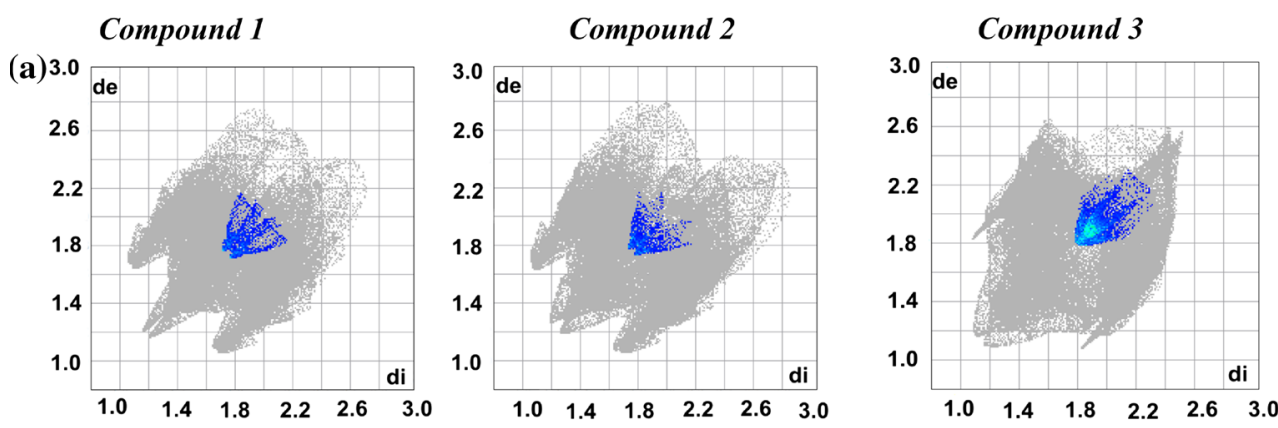

(b)
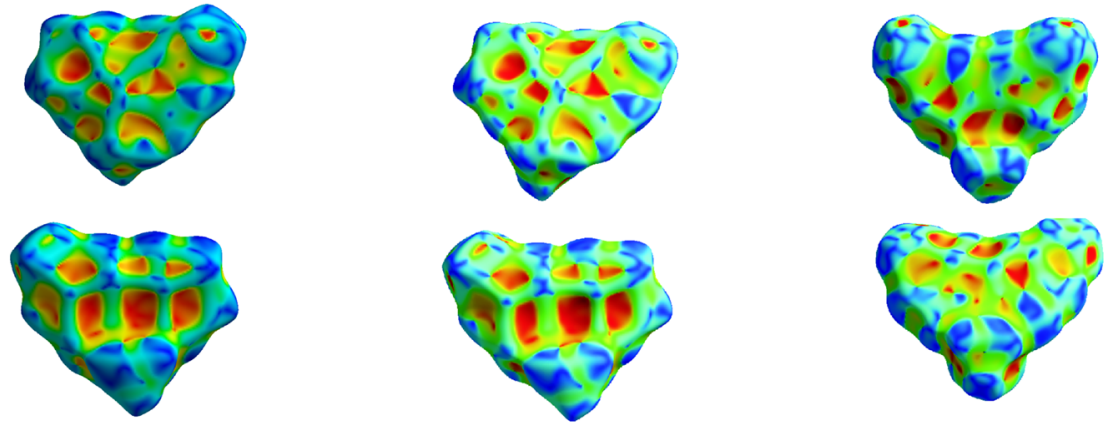

Compound 4

(a) ${ }^{3.0}$

(b)
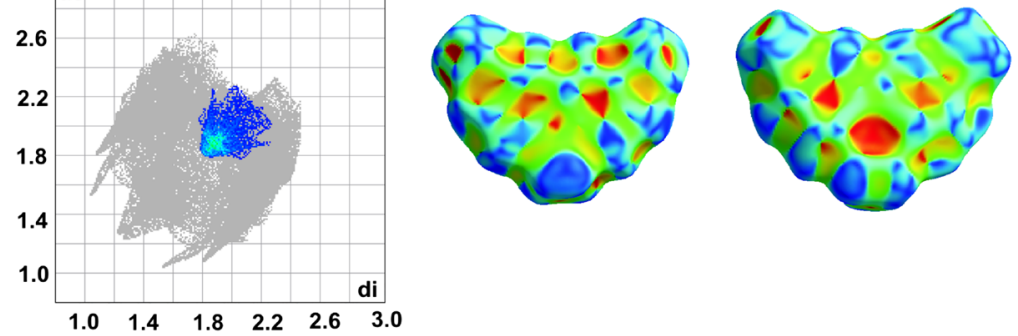

(a) 3.0

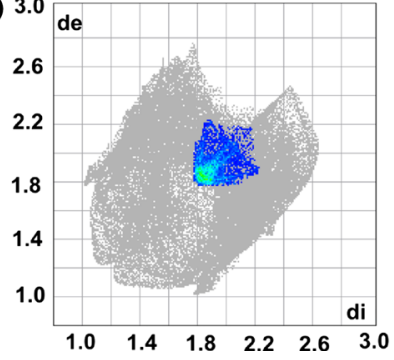

Compound 6

(b)
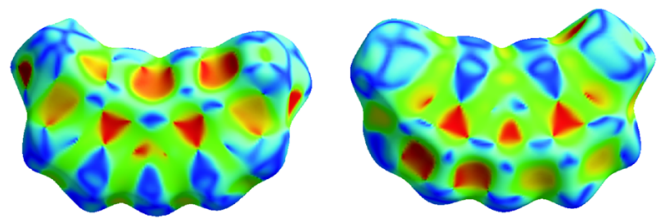

typical herringbone arrangement of molecules, it may be concluded that the slipped face-to-face $\pi \cdots \pi$ interactions in the crystals of mono-substituted halogen derivatives of ethylcarbazole (1 and $\mathbf{2}$ ) are a consequence of the presence of halogen substituents at position 3 , and the molecular packing into stacks with substantial $\mathrm{AO}$ between adjacent molecules in dibromo derivatives of carbazole, methyl- and ethylcarbazole $(\mathbf{3}, \mathbf{4}$, and $\mathbf{6})$, is caused by the presence of the second substituent of this type at position 6 . It is noteworthy that the extent of this overlap increases as the length of substituent at position 9 decreases, and as the ratio of $(\% \mathrm{C} \cdots \mathrm{H}) /(\% \mathrm{C} \cdots \mathrm{C})$ interactions decreases. Bearing in mind that the materials giving $\pi$-stacking in the solid state are particularly attractive because they often lead to devices with high charge-carrier mobilities, and taking into account the fact that in the crystal structures of the three above compounds the slipped $\pi$ stacking is predominant, it can be supposed that among nine analyzed here carbazole derivatives, they will turn out to be the most promising materials for device applications, particularly in the area of OFETs. 
Fig. 12 Relative contributions of intermolecular contacts to the Hirshfeld surface area in compounds $\mathbf{1}$ and $\mathbf{2}$, and in their eight simple analogs 3-10 retrieved from CSD (Color figure online)

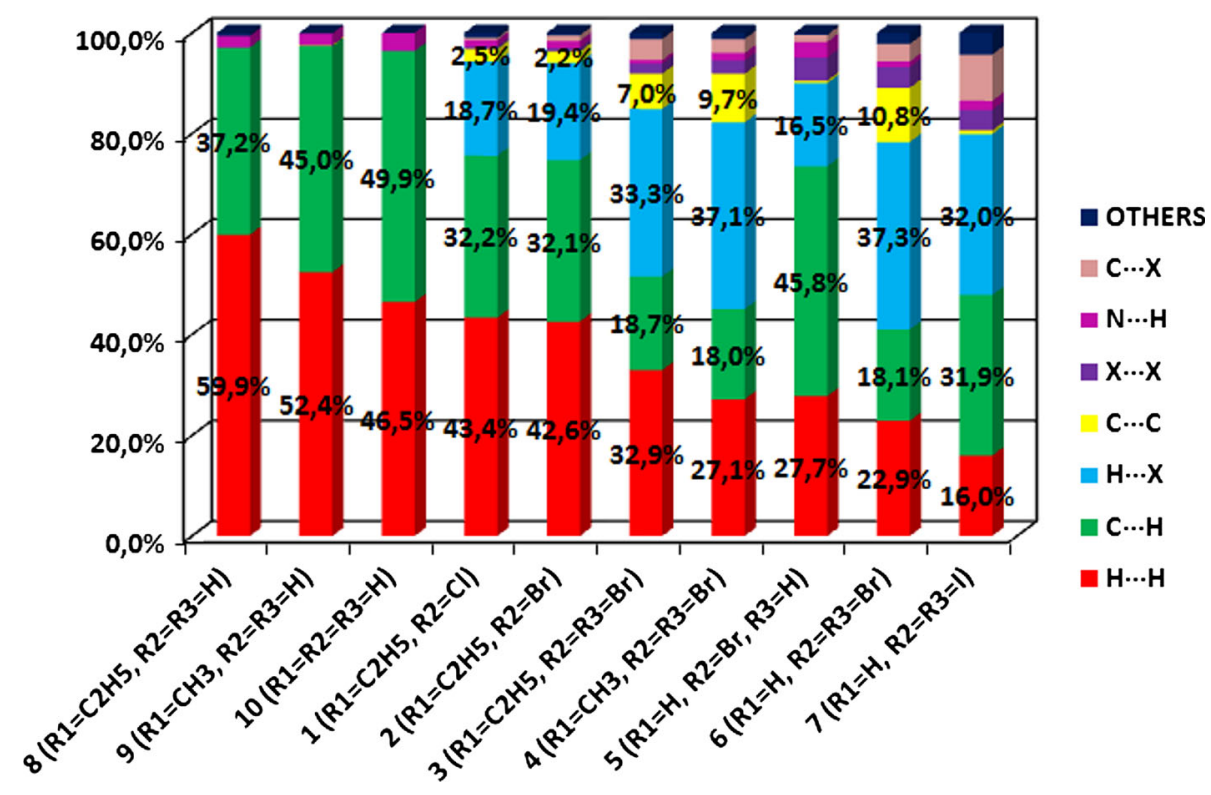

Open Access This article is distributed under the terms of the Creative Commons Attribution License which permits any use, distribution, and reproduction in any medium, provided the original author(s) and the source are credited.

\section{References}

1. Murphy AR, Fréchet JMJ (2007) Organic semiconducting oligomers for use in thin film transistors. Chem Rev 107:1066-1096

2. Mas-Torrent M, Rovira C (2008) Novel small molecules for organic field-effect transistors: towards processability and high performance. Chem Soc Rev 37:827-838

3. Huang J, Xu B, Lam M-K, Cheah K-W, Chen ChH, Su JH (2011) Unsymmetrically amorphous 9,10-disubstituted anthracene derivatives for high-efficiency blue organic electroluminescence devices. Dyes Pigm 89:155-161

4. Lai SL, Tong QX, Chan MY, Ng TW, Lo MF, Ko CC, Lee ST, Lee CS (2011) Carbazole-pyrene derivatives for undoped organic light-emitting devices. Org Electr 12:541-546

5. Chen R-F, Xie G-H, Zhao Y, Zhang S-L, Yin J, Liu S-Y, Huang W (2011) Novel heterofluorene-based hosts for highly efficient blue electrophosphorescence at low operating voltage. Org Electr 12:1619-1624

6. Kwon J, Hong J-P, Lee W, Noh S, Lee Ch, Lee S, Hong J-I (2010) Naphtho[2,3, a]pyrene as an efficient multifunctional organic semiconductor for organic solar cells, organic light-emitting diodes, and organic thin-film transistors. Org Electr 11:1103-1110

7. Carst-Powell Y (2005) Laser Focus World 41:40

8. Kim YH, Park SK, Moon DG, Kim WK, Man JI (2004) Organic thin film transistor-driven liquid crystal displays on flexible polymer substrate. Jpn J Appl Phys 43:3605-3608

9. Dodabalapur A (2006) Organic and polymer transistors for electronics. Mater Today 9:24-30

10. Bredas JL, Calbert JP, da Silva DA, Cornil J (2002) Organic semiconductors: a theoretical characterization of the basic parameters governing charge transport. PNAS 99:5804-5809

11. Cornil J, Beljonne D, Calbert JP, Bredas JL (2001) Interchain interactions in organic $\pi$-conjugated materials: impact on electronic structure, optical response, and charge transport. Adv Mater 13:1053-1067
12. Janzen DE, Burand MW, Ewbank PC, Pappenfus TM, Higuchi H, da Silva Filho DA, Young VG, Bredas JL, Mann KR (2004) Preparation and characterization of $\pi$-stacking quinodimethane oligothiophenes. Predicting semiconductor behavior and bandwidths from crystal structures and molecular orbital calculations. J Am Chem Soc 126:15295-15308

13. Curtis MD, Cao J, Kampf JW (2004) Solid-state packing of conjugated oligomers: from $\pi$-stacks to the herringbone structure. J Am Chem Soc 126:4318-4328

14. Anthony JE (2006) Functionalized acenes and heteroacenes. Chem Rev 106:5028-5048

15. Winzenberg KN, Kemppinen P, Fanchini G, Bown M, Collis GE, Forsyth CM, Hegedus K, Singh ThB, Watkins SE (2009) Dibenzo[b, def]chrysene derivatives: solution-processable small molecules that deliver high power-conversion efficiencies in bulk heterojunction solar cells. Chem Mater 21:5701-5703

16. Briseno AL, Miao Q, Ling M-M, Reese C, Meng H, Bao Z, Wudl F (2006) Hexathiapentacene: structure, molecular packing, and thin-film transistors. J Am Chem Soc 128:15576-15577

17. Moon H, Zeis R, Borkent EJ, Besnard C, Lovinger AJ, Siegrist T, Kloc C, Bao Z (2004) Synthesis, crystal structure, and transistor performance of tetracene derivatives. $J$ Am Chem Soc 126:15322-15323

18. Mas-Torrent M, Durkut M, Hadley P, Ribas X, Rovira R (2004) High mobility of dithiophene-tetrathiafulvalene single-crystal organic field effect transistors. J Am Chem Soc 126:984-985

19. Rozycka-Sokolowska E, Marciniak B (2009) 4-Chloro-1-naphthol. Acta Cryst C65:0207-o210

20. Rozycka-Sokolowska E, Marciniak B (2009) 5-Amino-1-naphthol: two-dimensional sheets built up from R44 (18) rings formed by $\mathrm{O}-\mathrm{H} \cdots \mathrm{N}, \mathrm{N}-\mathrm{H} \cdots \mathrm{O}$ and $\pi \cdots \pi$ interactions. Acta Cryst C65:0565-0568

21. Marciniak B, Rozycka-Sokolowska E (2009) 4-Methoxy-1naphthol: chains formed by $\mathrm{O}-\mathrm{H} \cdots \mathrm{O}$ hydrogen bonds and $\pi \cdots \pi$ stacking interactions. Acta Cryst C65:0630-o634

22. Allen FH (2002) The Cambridge structural database: a quarter of a million crystal structures and rising. Acta Cryst B58:380-388

23. Rozycka-Sokolowska E, Marciniak B, Pavlyuk V (2004) Redetermination of 1-naphthalenol. Acta Cryst E60:0884-0885

24. Gaultier J, Hauw C (1967) Structure cristalline et moléculaire de la naphtohydroquinone-1,4. Acta Cryst 23:1016-1024 
25. Bellows JC, Stevens ED, Prasad PN (1978) Chemical perturbation and lattice instability in molecular crystals: crystal structures and molecular motions of 1,4-dihalonaphthalenes. Acta Cryst B34:3256-3261

26. Trotter J (1986) 1,4-Dibromonaphthalene: a redetermination. Acta Cryst C42:351-353

27. Belskii VK, Kharchenko EV, Sobolev AN, Zavodnik VE, Kolomiets NA, Prober GS, Oleksenko LP (1990) Crystal and molecular structures of the isomers of dihydroxynaphthalenes. The effect of structure on the ice-forming properties. Zh Strukt Khim 31:116-121

28. Marciniak B, Rozycka-Sokolowska E, Pavlyuk V (2006) Naphthalene-1,3-diol. Acta Cryst C62:068-o70

29. Marciniak B (2007) Naphthalene-1,6-diol: a three-dimensional framework built from $\mathrm{O}-\mathrm{H} \cdots \mathrm{O}, \mathrm{O}-\mathrm{H} \cdots \pi$ and $\mathrm{C}-\mathrm{H} \cdots \mathrm{O}$ hydrogen bonds. Acta Cryst C63:0419-0422

30. Marciniak B (2007) Naphthalene-1,7-diol. Acta Cryst C63:0252o254

31. Rozycka-Sokolowska E, Marciniak B, Pavlyuk V (2005) Naphthalene-2,7-diol. Acta Cryst E61:o114-o115

32. Marciniak B, Rozycka-Sokolowska E, Pavlyuk V (2003) 2- Naphthalenol. Acta Cryst E59:052-o53

33. Bodzioch A, Marciniak B, Rozycka-Sokolowska E, Jeszka JK, Uznański P, Kania S, Kuliński J, Bałczewski P (2012) Synthesis and optoelectronic properties of Hexahydroxylated 10-O-R substituted anthracenes via a new modification of the FriedelCrafts reaction using O-protected ortho-Acetal diarylmethanols. Chem Eur J 18:4866-4876

34. Bałczewski P, Bodzioch A, Rozycka-Sokolowska E, Marciniak B, Uznański P (2010) First approach to nitrogen-containing fused aromatic hydrocarbons as targets for organoelectronics utilizing a new transformation of O-protected diaryl methanols. Chem Eur J 16:2392-2400

35. Huang P-M, Li J-S, Duan X-M, Zeng T, Yan X-L (2005) 3,6Dibromo-9-ethyl-9H-carbazole. Acta Cryst E61:02366-o2367

36. Belloni M, Kariuki BM, Manickam M, Wilkie J, Preece JA (2005) Design of potentially photorefractive liquid crystalline materials: derivatives of 3,6-disubstituted carbazole. Cryst Growth Des 5:1443-1450

37. Tavasli M, Bettington S, Bryce MR, Batsanov AS, Monkman AP (2005) Practical syntheses of $N$-Hexylcarbazol-2-yl- and -3-ylboronic Acids, their cross-coupled products and a derived Triscyclometalated (Pyridin-2-yl)carbazole iridium(III) complex. Synthesis 1619-1625

38. Xie Y-Z, Jin J-Y, Jin G-D (2012) 3,6-Diiodo-9H-carbazole. Acta Cryst E 68:01242

39. Kimura T, Kai Y, Yasuoka N, Kasai N (2006) The crystal and molecular structure of $N$-ethylcarbazole. Bull Chem Soc Jpn 58:2268-2271

40. Popova EG, Chetkina LA (1985) X-ray structural study of $N$ methylcarbazole. J Struct Chem 20(564):569

41. Belskii VK (1985) Structure of carbazole. Kristallografiya 30:193-194

42. Morin J-F, Leclerc M, Ades D, Siove A (2005) Polycarbazoles: 25 years of progress. Macromol Rapid Commun 26:761-778

43. Drolet N, Morin JF, Leclerc N, Wakim S, Tao Y, Leclerc M (2005) 2,7-carbazolenevinylene-based oligomer thin-film transistors: high mobility through structural ordering. Adv Funct Mater 15:1671-1682

44. Wakim S, Bouchard J, Simard M, Drolet N, Tao Y, Leclerc M (2004) Organic microelectronics: design, synthesis, and characterization of 6,12-dimethylindolo[3,2-b]carbazoles. Chem Mater 16:4386-4388

45. Li Y, Wu Y, Gardner S, Ong BS (2005) Novel peripherally substituted indolo[3,2- $b$ ]carbazoles for high-mobility organic thin-film transistors. Adv Mater 17:849-853

46. Wu Y, Li Y, Gardner S, Ong BS (2005) Indolo[3,2- $b$ ]carbazolebased thin-film transistors with high mobility and stability. J Am Chem Soc 127:614-618

47. Boudreault PLT, Wakim S, Blouin N, Simard M, Tessier C, Tao Y, Leclerc M (2007) Synthesis, characterization, and application of indolo[3,2- $b]$ carbazole semiconductors. J Am Chem Soc 129:9125-9136

48. Boudreault P-LT, Wakim S, Tang ML, Tao Y, Bao Z, Leclerc M (2009) New indolo[3,2-b]carbazole derivatives for field-effect transistor applications. J Mater Chem 19:2921-2928

49. Leclerc N, Michaud A, Sirois K, Morin JF, Leclerc M (2006) Synthesis of 2,7-carbazolenevinylene-based copolymers and characterization of their photovoltaic properties. Adv Funct Mater 16:1694-1704

50. Blouin N, Michaud A, Michaud A, Gendron D, Wakim S, Blair E, Neagu-Plesu R, Belletete M, Durocher G, Tao Y, Leclerc M (2008) Toward a rational design of poly(2,7-Carbazole) derivatives for solar cells. J Am Chem Soc 130:732-742

51. Levesque I, Bertrand PO, Blouin N, Leclerc M, Zecchin S, Zotti G, Ratcliffe CI, Klug DD, Gao X, Gao F, Tse JS (2007) Synthesis and thermoelectric properties of polycarbazole, polyindolocarbazole, and polydiindolocarbazole derivatives. Chem Mater 19:2128-2138

52. Wakim S, Aïch B-R, Tao Y, Leclerc M (2008) Charge transport, photovoltaic and thermoelectric properties of poly (2,7-carbazole) and poly(indolo[3,2-b]carbazole) derivatives. Polym Rev 48:432-462

53. Pansay S, Prachumrak N, Jungsuttiwong S, Keawin T, Sudyoadsuk T, Promarak V (2012) Multibromo- $N$-alkylcarbazoles: synthesis, characterization, and their benzo[b]thiophene derivative. Tetrahedron Lett 53:4568-4572

54. Sheldrick GM (2008) A short history of SHELX. Acta Cryst A64:112-122

55. Wolff SK, Grimwood DJ, McKinnon JJ, Turner MJ, Jayatilaka D, Spackman MA (2012) CrystalExplorer (Version 3.1). University of Western Australia

56. Spackman MA, Jayatilaka D (2009) Hirshfeld surface analysis. Cryst Eng Comm 11:19-32

57. Spackman MA, McKinnon JJ (2002) Fingerprinting intermolecular interactions in molecular crystals. Cryst Eng Comm 4:378-392

58. Kálmán A, Párkányi L, Argay G (1993) Classification of the isostructurality of organic molecules in the crystalline state. Acta Cryst B49:1039-1049

59. Kálmán A, Argay G, Scharfenberg-Pfeiffer D, Höhne E, Ribár B (1991) 'Main-part' isostructuralism of several cardenolides and bufadienolides. Structures of three cardenolides: (21S)-methyldigitoxigenin, uzarigenin and sarmentogenin methanol solvate. Acta Cryst B47:68-77

60. Bruno IJ, Cole JC, Kessler M, Luo J, Mortherwell WDS, Purkis LH, Smith BR, Taylor R (2004) Retrieval of crystallographicallyderived molecular geometry information. J Chem Inf Comput Sci 44:2133-2144

61. Giershner J, Park SY (2013) Luminescent distyrylbenzenes: tailoring molecular structure and crystalline morphology. J Mater Chem C 1:5818-5832 